\title{
Diagnosing Unhappiness Dynamics: Evidence from Poland and Russia
}

\author{
Michal Brzezinski ${ }^{1}$ (D) \\ Published online: 22 October 2018 \\ (C) The Author(s) 2018
}

\begin{abstract}
This paper studies the determinants of changes in unhappiness rate (low happiness, poverty of happiness, misery) over time. We focus on two post-socialist countries, Poland and Russia, which experienced radical social and economic transformations since the collapse of communism. Using data from the Polish Social Diagnosis project for 1991-2015 and data from the Russian Longitudinal Monitoring Survey for 1994-2014, we investigate the microeconomic determinants of spectacular declines in unhappiness rates observed in the studied periods in Poland (a 56\% fall in unhappiness) and Russia (a drop in the range from 46 to $75 \%$ depending on the unhappiness threshold chosen). Using a nonlinear decomposition methodology, we split the overall decreases in unhappiness rates into characteristics effects (related to the changing distribution of unhappiness-affecting factors) and coefficients effects (due to changing returns to the unhappiness-affecting factors). Our results show that unhappiness reductions in both countries were mostly driven by coefficient effects, while characteristics played a smaller, but a non-negligible role. In both countries, income growth accounted for about $15 \%$ of the total unhappiness reduction. In Russia, this effect was doubled by growing return to income as unhappiness-protecting factor, while in Poland income has been losing protecting power and in overall income had an unhappiness-increasing effect. For Russia, another strong unhappiness-protecting factor was return to employment. In case of Poland, good self-rated health and having children explains additional $15-20 \%$ of the unhappiness reduction.
\end{abstract}

Keywords Happiness · Unhappiness - Life satisfaction · Decomposition · Determinants · Poland · Russia

\section{Introduction}

In recent years, the problem of distribution of self-rated happiness has become a growing field of study at the intersection of economics of happiness (Dolan et al. 2008; MacKerron 2012; Weimann et al. 2015) and traditional literature on income poverty and inequality. Data on happiness come usually from surveys in which respondents are asked about

Michal Brzezinski

mbrzezinski@wne.uw.edu.pl

1 Faculty of Economic Sciences, Uniwersytet Warszawski, Warsaw, Poland 
their happiness with possible answers coded on a 3-11 point ordinal scale. Several recent studies have attempted to measure happiness inequality by applying inequality measures such as variance or the Gini index to happiness scores (see, e.g., Stevenson and Wolfers 2008; Dutta and Foster 2013; Becchetti et al. 2014). Much less attention has been devoted to exploring the concept of aggregate unhappiness or happiness poverty, which is defined as the proportion of population reporting low or unsatisfactory levels of happiness. One important exception is the study of Lelkes (2013), who have investigated the microeconomic correlates of unhappiness for 29 European countries observed in 2008/2009 using data from the European Social Survey (ESS). She has found that unhappiness is strongly related to observable social and economic individual characteristics such as unemployment, poverty and social isolation. At the same time, these characteristics are much less correlated with reporting high levels of happiness ("bliss").

In this paper, we contribute to the literature on unhappiness by identifying the individual microeconomic determinants of changes in unhappiness over time. To this end, we use a multivariate decomposition methodology developed by Yun $(2004,2005,2008)$, which is a nonlinear variant of the well-known Oaxaca-Blinder decomposition (Oaxaca 1973; Blinder 1973). ${ }^{1}$ The decomposition applied to nonlinear regressions for the probability of being unhappy allows to measure how the differences in the demographic, social, economic and labour characteristics of individuals and households contribute to the change in aggregate unhappiness rate over time. This contribution is called characteristics effect. The remaining part of the decomposed change in the unhappiness rate, which is usually called the coefficients effect, accounts for the changing returns to the characteristics and shows what is the aggregate impact of changes in returns on the unhappiness rate. The advantage of the Yun's $(2004,2005,2008)$ methodology is that it provides also the so-called detailed decomposition for both characteristics and coefficient effects into individual effects, which identify the separate contributions of each individual covariate affecting unhappiness. ${ }^{2}$ This allows to formulate specific policy recommendations (concerning policies related to education, labour market, inequality or poverty, etc.) that would minimize avoidable misery (Lelkes 2013).

This paper contributes to the literature in three ways. First, we identify factors contributing to the changes in unhappiness over time, which to our best knowledge has not been studied yet. Secondly, we analyse the determinants of unhappiness and changes in unhappiness over time for individual countries observed over a relatively long period. This increases the probability of obtaining less biased results than those of Lelkes (2013), which are based on the pooled sample of 29 European countries. Although Lelkes (2013) controls for observed heterogeneity in reporting happiness by including several control variables and country dummies in her estimations, there is also unobserved heterogeneity in

\footnotetext{
1 This methodology has been used extensively to explain differences in income poverty rates between various socio-economic or ethnic groups (see, e.g., Gang et al. 2006; Gradín 2009, 2012).

2 Several other nonlinear decomposition methodologies allow only for separating aggregate characteristics and coefficient effects, which account for a given effect of all covariates taken together. See Fortin et al. (2011) for a comprehensive review of decomposition methodologies in economics. An alternative approach providing also a detailed decomposition of differences or changes in given outcomes (e.g. incomes, happiness, health) is based on the so-called Recentered Influence Function (RIF) regressions. This methodology was used by Becchetti et al. (2014) to study the determinants of dynamics in happiness inequality. We prefer to use the Yun's methodology as it is slightly more suitable to use with nonlinear models. However, we have also applied the decomposition based on RIF regressions to our data and the results were in general robust to the choice of the methodology.
} 
reporting happiness due to different scales and benchmarks that people in different countries use to evaluate their happiness (see, e.g., Ferrer-i-Carbonell and Frijters 2004; Beegle et al. 2012; Angelini et al. 2014). ${ }^{3}$ This problem is somewhat reduced in the present paper as our analyses are performed separately for each country under study. Moreover, in the context of the present paper the problem of scale heterogeneity in reporting happiness is somewhat less relevant as our dependent variable is not the whole distribution of happiness scores, but only the proportion of people who report happiness no higher than a given unhappiness threshold. We also use a rich set of explanatory variables accounting for observed heterogeneity between individuals which includes socio-demographic individual characteristics, labour market variables, health indicators, wealth and income-related variables, social capital and religious preferences indicators, location and regional dummies, and others.

Thirdly, we contribute to the sizeable literature on the determinants of happiness in transition countries that underwent economic and political transformation from communism to democracy and market economies (see Selezneva 2011, 2016 and Sect. 2.2 in this paper for a review of this research). Our analysis is performed for two post-communist countries, Poland and Russia, that have experienced dramatic economic, social and political changes in the process of transformation during the last 25 years. The choice of the countries and the period of analysis - from the early 1990s to the mid-2010s - is dictated by the fact that the transition process has produced in these countries large changes both in the correlates of happiness/unhappiness and also in the mean levels and in the distribution of happiness itself. In particular, as shown in Sect. 4, the changes in unhappiness rates (proportions of persons reporting low levels of happiness) have been unusually large for Poland and Russia during the last 25 years. For Poland, the unhappiness rate has fallen by $56 \%$ between 1991 and 2015, while in Russia the fall is in the range from 46 to $75 \%$ depending on the unhappiness threshold chosen. We use survey data from the Polish Social Diagnosis project (Czapinski and Panek 2015), which covers the period from 1991 to 2015, and data from the Russian Longitudinal Monitoring Survey (RLMS) covering the years 1994-2014. The latter dataset has been extensively used to study happiness in Russia in previous research (see, e.g., Graham et al. 2004; Senik 2004; Frijters et al. 2006). There are also a few papers using the Social Diagnosis survey to study happiness in Poland (Baranowska and Matysiak 2011; Michoń 2014). Both data sets deliver high-quality data on happiness and its potential correlates, while at the same time offering much bigger samples than the commonly used happiness data from the international projects such as the ESS or the World Values Survey (WVS).

The reminder of the paper is organized in the following way. Section 2 provides a short review of the literature studying inequality and poverty in terms of happiness as well as literature on the determinants of happiness in transition countries. The decomposition methodology is introduced in Sect. 3, while the data and trends in unhappiness in Poland and Russia are discussed in Sect. 4. We present our main empirical results in Sect. 5 and conclusions in Sect. 6.

\footnotetext{
3 One can deal with this problem when panel data are available by using regression models with fixed or random effects or latent class techniques. In case of cross-sectional data, anchoring vignettes methodology may be used to correct for individual-specific biases in happiness scales and benchmarks (Angelini et al. 2014). In this paper, we do not use these approaches as we are dealing with cross-sectional data without anchoring vignettes.
} 


\section{A Review of Related Literature}

\subsection{Measuring the Distribution of Happiness}

Most of the existing research on the distribution of happiness focuses rather on inequality of happiness than on poverty of it. ${ }^{4}$ The literature on happiness inequality can be divided into the macroeconomic and the microeconomic branch. The former is devoted to measuring the correlations between happiness inequality and macroeconomic phenomena like the GDP growth or economic fluctuations. Veenhoven (1990, 2005a) found that there is less happiness inequality in richer and more stable economies, while Veenhoven (2005b) discovered that happiness inequality was falling in the EU countries between 1973 and 2001, despite growing income inequality. Ovaska and Takashima (2010) observed that in the cross-country setting happiness inequality is correlated with income inequality, health inequality and bad institutions. The relation between happiness inequality, good governance and the size of government was studied by Ott (2013). Clark et al. (2014) have found that happiness inequality (as measured by the coefficient of variation applied to happiness scores) is falling over recent decades in Australia, Great Britain, Germany and the United States. ${ }^{5}$ Moreover, there is a positive association between real GDP per capita growth and lower levels of happiness inequality. The results of Clark et al. (2014) suggest also that the percentages of population with either very high or very low happiness are declining in the studied countries. In our context, it means that unhappiness in rich countries, at least for the specific low happiness thresholds assumed by Clark et al. (2014), has been falling in recent decades. Clark et al. (2015) show further that happiness inequality has been falling in the countries that experienced consistent income growth, but not in countries with some periods of falling real GDP per capita. The authors suggest that decreasing happiness inequality is associated with the greater supply of public goods such as education, health, public infrastructure and social protection.

The second strand of empirical research on happiness inequality explores microeconomic determinants of this kind of inequality. Stevenson and Wolfers (2008) and Dutta and Foster (2013) have applied various measures of inequality to happiness scores for US data from the General Social Survey (GSS). Both studies have found decreasing happiness inequality from the early 1970s up to 1990s, which was somewhat reversed in the 2000s. Both studies provide also microeconomic decompositions of overall happiness inequality by gender and race. In an important study, Becchetti et al. (2014) have studied the evolution of happiness inequality in Germany between 1992 and 2007. Using RIF regressions (see Fortin et al. 2011), they have decomposed changes in inequality of happiness (as measured by the variance and the Gini of happiness scores) observed between two periods 1991-1993 and 2005-2007. They have found that changes in happiness inequality are accounted for mainly by characteristics effects, while the coefficient effects are not significant. Among the characteristics effects, medium and high education as well as growth

\footnotetext{
${ }^{4}$ In this paper, we assume that happiness and life satisfaction denote the same dimension of subjective well-being. Although measures of well-being are often divided into hedonic (happiness), cognitive (life satisfaction) and eudemonic (meaning, flourishing, accomplishment), it is difficult to disentangle hedonic from cognitive elements of well-being. Clark and Senik (2011) and Clark (2016) treat happiness and life satisfaction as a common "hedonic" dimension of well-being and show that these measures are very significantly correlated in practice.

5 With the exception that happiness inequality started to grow in recent years for the United States.
} 
in average incomes had a sizable inequality-reducing impact. Increases in unemployment had a large inequality-increasing effect, while changes in both absolute and relative income poverty and richness had no or little impact. The decompositions based on RIF regressions have been recently also used to investigate happiness inequality in China (Yang et al. 2015) and Japan (Niimi 2015). Finally, Goff et al. (2016) argued recently that happiness inequality affects negatively average happiness and social trust more strongly than income inequality does.

In comparison with relatively rich literature on happiness inequality, the research on happiness poverty is rather scarce. Binder and Coad (2011) have applied quantile regression techniques to British data for 2006 to study correlates of happiness at different quantiles of happiness distribution. Their major findings include decreasing importance of income, health status and social factors with increasing quantiles of happiness, as well as positive association between education and happiness at lower quantiles, but a negative one at higher ones. Lelkes (2013) have used data from ESS pooled for 29 European countries observed in 2008/2009. The ESS contained both life satisfaction and happiness questions, both coded on a scale from 0 (extremely dissatisfied or extremely unhappy) to 10 (extremely satisfied or extremely happy). ${ }^{6}$ Lelkes (2013) have estimated regressions for both low life satisfaction and low happiness obtaining very similar results for both measures. As a threshold separating low values of happiness or life satisfaction she has chosen score equal to 3 and, in robustness analysis, equal to 5 . The results for both thresholds were very close. The main results suggest that for the ESS sample in 2008/2009 unhappiness and low life satisfaction are correlated positively with being in the first or second income quintile group, being unemployed or inactive, feeling lonely, having bad health, being a member of ethnic minority and being never or no longer married (separated, divorced or widowed).

The correlates of happiness poverty were also studied empirically by Kingdon and Knight (2006) and Wang et al. (2011). The former study found that being dissatisfied or very dissatisfied with life in South Africa in 1993 is positively associated with income, living in urban area, being non-White and being unemployed. The latter paper investigated poor or very poo life satisfaction among the Chinese rural elderly population in 2006. The most significant correlates of unhappiness poverty included poor health and income poverty.

Finally, recently Bjørnskov and Ming-Chang (2015) have investigated the association between institutional factors and four categories of happiness (unhappy, moderately dissatisfied, moderately satisfied, and happy) using cross-country data from the WVS. They found that legal quality and social trust are correlated with less unhappiness for all countries. Democracy was found to reduce unhappiness only in rich countries, while religiosity has the same effect only in poor countries.

\subsection{Happiness and Unhappiness in Eastern Europe}

The most well-known single fact about the evolution of happiness in Eastern European post-communist countries is the "happiness gap"-a significant and persistent difference between average happiness in Eastern Europe and Western countries (Guriev and

\footnotetext{
6 The life satisfaction question in ESS is: "All things considered, how satisfied are you with your life as a whole nowadays?". The happiness question is: "How happy are you?".
} 
Zhuravskaya 2009; Djankov et al. 2016). Guriev and Zhuravskaya (2009) have used the WVS data to estimate the happiness gap for the post-communist transition countries. The subjective well-being question from the WVS they used concerned life satisfaction with answers coded on a scale from 0 to 10 . The authors found that the average life satisfaction in transition countries was lower than the predicted value for all countries studied in the WVS by 1.4 points for the WVS wave 3 (1994-1999) and by 1.13 points for the WVS wave 4 (1999-2003). They suggested that the gap results from several factors: the depreciation of human capital stock accumulated under socialism in face of new market economy conditions, increasing income inequality, income volatility and uncertainty, changes in the aspiration level and the decrease in quality and quantity of public goods supply. Guriev and Zhuravskaya (2009) expected that the gap will slowly disappear with continued economic growth and convergence of the GDP in Eastern Europe to the Western levels. Recently, Djankov et al. (2016) have shown that although the gap narrowed somewhat between 1990 and the early 2000s, it still persists at a non-negligible level. The authors have found that the gap disappears if perceived political corruption and low quality of governance in Eastern Europe is taken into account.

The reminder of this section is devoted to the short review of the determinants of individual happiness in transition countries. We follow closely the recent review of Selezneva (2016). Easterlin (2009) observed that life satisfaction in transition countries has followed closely changes in the GDP-it dropped sharply in the late 1980s and early 1990s and recovered as the GDP started to increase since the mid- or late-1990s. According to Easterlin (2009), the drastic decline of life satisfaction in the early phase of transition should be explained by loss aversion associated with stagnating labour market and deteriorating social safety net. Easterlin (2009) suggested also that the transition brought life satisfaction gains rather to the young (under 30) persons-an observation confirmed also by Guriev and Zhuravskaya (2009).

Senik (2004) has found a negative happiness gap for women in Russia. This finding is opposite to those established for women in Western countries. However, later studies have suggested that this gender gap in happiness is closing in Russia (see Selezneva 2016). As far as family relations are concerned, several studies observed a positive relationship between marriage and individual happiness in Poland (Angelescu 2008) and other transition countries (Selezneva 2016). Baranowska and Matysiak (2011) have found that in Poland there is a positive effect of the first child on happiness of mothers, but only a small and temporary effect for fathers. For Russia, Mikucka (2015) established that life satisfaction does not increase with the birth of first child, but only after the birth of the second one. Contrary to what is characteristic for Western countries, she has also estimated a positive long-term effect of parenthood on life satisfaction in Russia.

The absolute income hypothesis, which suggests that for a given society richer people are happier than poorer people, have been confirmed for transition countries (Senik 2004; Hayo 2007). Similarly, the diminishing marginal utility hypothesis suggesting that there are decreasing gains from income for wealthy people was also verified positively. Guriev and Zhuravskaya (2009) and Frijters et al. (2006) found also that the effect of absolute income on happiness is much bigger in transition countries than in other countries. The familiar Easterlin paradox (showing that happiness and GDP are unrelated over time) did not occur in Russia (Frijters et al. 2006; Guriev and Zhuravskaya 2009) and some other transition countries, but not in all of them.

The relative income hypothesis assumes that there is a negative impact of the reference income on individual subjective well-being (Van Praag 2011). Reference income is the average income of the group of people to which a given person compares herself; the 
reference group may be defined as neighbours, colleagues, occupation group, age group, etc. Some positive evidence for relative income hypothesis was found in the poorest areas of transition countries (Selezneva 2016). However, for several richer post-communist countries Senik $(2004,2008)$ verified the existence of the so-called tunnel effect, which violates the relative income hypothesis. This effect suggest that the growing income of the reference group can be interpreted by members of this group as a sign of positive expectations about their own incomes in near future. Senik $(2004,2008)$ have shown that the "tunnel" effect operated in Russia, Hungary and Poland from the mid- to late 1990s.

The evidence that unemployment was associated with lower happiness in transition countries was provided, among others, by Hayo and Seifert (2003). For Poland, Angelescu (2008) found that the trend in life satisfaction mirrored rather the evolution of the unemployment rate than that of the GDP. In Russia during the 1990s, inactivity was associated with higher happiness than working with arrears and unemployment, but in other countries including Poland labour market participants were on average happier than inactive persons (Selezneva 2016).

A well-known finding from happiness economics literature is that happiness is highly correlated with health (see, e.g., Dolan et al. 2008). In the context of transition countries, Kolosnitsyna et al. (2014) have found that self-rated health is one of the strongest predictors of happiness among older Russians. Graham and Felton (2005) estimated the relationship between happiness and being overweight or obese in Russia over 1995-2001. A surprising result was that in Russia there was a positive relationship between obesity and happiness. There was no robust effect of being overweight on happiness. The authors suggested that these results are driven by the fact that obesity (especially among men) in Russia was more widespread among richer people.

Bartolini et al. (2015) have shown that social capital (as proxied by social trust) is an important determinant of happiness in transition countries. In fact, over the medium run (4-6 years) social capital contributes to happiness as much as the GDP. Popova (2014) has found that religiosity insures against drop in happiness and helps to have positive perceptions of economic and political situation in times of reforms. ${ }^{7}$ Okulicz-Kozaryn (2015) stressed the importance of self-reported freedom on life satisfaction in transition countries. Several papers (e.g. Hayo 2007) have also shown that in transition countries people living in rural areas are happier than those living in more urbanized areas or in big cities. This can be explained by lower cost of living in rural areas and smaller cities and by faster pace of changes in the aspiration level of people living in big cities.

Finally, Sanfey and Teksoz (2007) and Guriev and Zhuravskaya (2009) have found a negative link between income inequality and happiness in transition countries. This may be a consequence of huge increases in income inequality, especially during the early transition in 1990s. Milanovic (1999) estimated that the Gini index grew in Russia from 0.22 to 0.52 between 1989 and 1996, while from 0.25 to 0.36 in the same period in Poland. ${ }^{8}$ Responding to this inequality spike, Polish citizens stopped to perceive inequality as a signal of increasing opportunities and started to express significant aversion to inequality in

\footnotetext{
7 Notice, however, that Djankov et al. (2016) show that Eastern Orthodox religion accounts for about 30\% of the happiness gap between Eastern Europe and Western countries. This may be due to the emphasis of this religion on such practices as fasting, reflection and prayer.

8 As shown by Ferreira and Ravallion (2009) and Alvaredo and Gasparini (2015), absolute income poverty increased in Eastern Europe in the early 1990 s, but started to fall rapidly since the mid-1990 s or after 1998 in Russia.
} 
the second half of the 1990s (Grosfeld and Senik 2010). Recently, Cojocaru (2014) has studied the relationship between inequality aversion and life satisfaction using survey data for 27 transition countries from the first round of the Life in Transition Survey conducted by the EBRD and the World Bank in $2006 .{ }^{9}$ He found that relative deprivation within reference groups (individuals within given census enumeration areas) is negatively correlated with life satisfaction for transition countries, while there is no link between life satisfaction and aggregate inequality measured on the country level.

\section{Methods}

One of the major methodological issues related to the problem of measuring inequality of happiness is the fact that self-reported variables are measured on the ordinal scale, while most of the existing inequality measures are suitable only for cardinal variables such as income or consumption expenditure. Some of the relevant research argues that since treating happiness as either cardinal or ordinal does not matter empirically much in regression models explaining happiness (Ferrer-i-Carbonell and Frijters 2004), one can simply assume cardinality of happiness and apply standard inequality measures as the Gini index or variance. Other approaches rely on using special ordinal inequality measures that where explicitly designed for variables measured on the ordinal scale (see, e.g., Dutta and Foster 2013). However, in this paper we are dealing with the problem of happiness poverty (unhappiness), which does not require the assumption of happiness cardinality. Our dependent variable is an unhappiness rate defined as a proportion of unhappy persons in the population. For a numerical happiness scale $s=(a, \ldots, k, \ldots b)$, where $a$ represents a number assigned to the lowest state of happiness and $b$ denotes the highest state of happiness, $k$ represents a chosen unhappiness threshold and the unhappiness rate is the proportion of population with self-rated happiness score equal or less than $k$. Notice, that there may be several sensible choices of $k$, especially for happiness scales with higher values of $b .{ }^{10}$ We further discuss our choice of $k$ in Sect. 4, when presenting our happiness data for Poland and Russia.

In order to identify factors that are associated with changes in unhappiness over time, we use a variant of multivariate regression-based decomposition techniques, which are routinely applied in labour economics and income distribution literature to account for changes in mean outcomes (e.g. wages) between various socio-economic groups (e.g. men versus women) or for changes in these outcomes over time. In case of decomposing differences in mean outcomes between groups or over time, this approach is known as the Oaxaca-Blinder methodology (Oaxaca 1973; Blinder 1973). The methodology allows to partition the observed differences in a mean outcome (wage, self-rated happiness or health, etc.) between groups or over time into a component attributable to differences in the observed characteristics (i.e. individual demographic, economic or educational attributes) and a component attributable to differences in the returns to these characteristics. The characteristics component is often also called the endowments effect, while the latter is called the coefficients effect.

\footnotetext{
9 Cojocaru and Diagne (2015) and Nikolova and Sanfey (2016) have studied the consistency and reliability of life satisfaction data collected in Life in Transition Survey.

${ }^{10}$ In many surveys, the number of categories for happiness question reaches 7 (British Household Panel Survey), 10 (WVS) or 11 (German Socio-Economic Panel). On the other hand, the US GSS contains a happiness question with only 3 -point response scale.
} 
The original Oaxaca-Blinder methodology based on linear regression models is designed for decomposing differences in mean outcomes between groups or over time. However, in this paper we are rather concerned with decomposing changes in the incidence of unhappiness (or poverty in terms of self-rated happiness) over time. To this end, we can use an extension of the Oaxaca-Blinder approach to non-linear models, which has been used, among others, to study the differences in income poverty incidence (Bhaumik et al. 2006; Gang et al. 2006; Gradín 2009, 2012). In our context, we are interested in explaining changes in the probability of reporting low level of happiness $(H), \operatorname{Pr}(H \leq k)$, where $k$ is the chosen cut-off level separating individuals with low happiness from individuals with medium or high level of happiness. Under a logit probability model, the likelihood of a person $i$ having a low level of happiness in time $t, P_{i}^{t}(k)$, can be written as:

$$
P_{i}^{t}(k)=\operatorname{Pr}\left(H_{i}^{t} \leq k\right)=F\left(X_{i}^{t} \hat{\beta}^{t}\right)=\frac{\exp \left(X_{i}^{t} \hat{\beta}^{t}\right)}{1+\exp \left(X_{i}^{t} \hat{\beta}^{t}\right)}
$$

where $F$ is the logistic probabilistic cumulative distribution, $X_{i}^{t}$ is a vector of independent variables or characteristics describing the individual $i$ in period $t$, and $\hat{\beta}^{t}$ is the vector of estimated coefficients or returns to these characteristics. The logit regressions (1) are estimated separately for Poland and Russia and for each period under study. The straightforward statistical specification (1) allows for measuring the association between unhappiness and each individual attribute included in $X$ when other individual characteristics are controlled for, but of course precludes inference about the direction of causality between happiness and factors included in $X$.

For the logit model, the incidence of unhappiness in period $t, U H^{t}$, is equal to the average predicted probability of having low happiness (see, e.g., Bhaumik et al. 2006) ${ }^{11}$ :

$$
U H^{t}=\bar{P}^{t}(k)=\overline{F\left(X_{i}^{t} \hat{\beta}^{t}\right)} .
$$

Using property (2), the difference between the incidence of unhappiness observed in two periods $t=0$ and $t=1$,

$$
U H^{1}-U H^{0}=\bar{P}^{1}(k)-\bar{P}^{0}(k)=\overline{F\left(X^{1} \beta^{1}\right)}-\overline{F\left(X^{0} \beta^{0}\right)},
$$

can be decomposed into the aggregate characteristics or endowments effect, $E$, and aggregate coefficients effect, $C$ :

$$
U H^{1}-U H^{0}=E+C=\left\{\overline{F\left(X^{1} \beta^{1}\right)}-\overline{F\left(X^{0} \beta^{1}\right)}\right\}+\left\{\overline{F\left(X^{0} \beta^{1}\right)}-\overline{F\left(X^{0} \beta^{0}\right)}\right\} .
$$

\footnotetext{
11 The average predicted probability is equal to the mean of dependent variable also for other models such as the linear and Poisson regressions. However, this equality does not hold for other models like the probit, negative binomial and complementary log-log regressions.
} 
In Eq. (4), we assume that period 1 is the comparison period and period 0 is the reference period. ${ }^{12}$ From this perspective, $E$ represents a counterfactual difference over time in unhappiness if the distribution of covariates in period 1 would be as in period 0 . On the other hand, the effect $C$ reflects a counterfactual difference over time in $U H$ if in period 0 coefficients associated with covariates (or returns to the elements of $X$ ) would be such as in the period 1 .

Equation (4) gives the aggregate decomposition of a change in the outcome over time. In order to identify the contribution of each individual covariate to the change in the observed difference in $U H$, one needs to perform a detailed decomposition. The detailed decomposition allows to partition the aggregate effects $E$ and $C$ into individual effects $E_{g}$ and $C_{g}, g=1, \ldots, G$, representing the contributions of an individual $g$ th element of $X$ to the aggregate effects $E$ and $C$. In case of regression-based decompositions based on non-linear models such as the logit, a useful detailed decomposition was proposed by Yun (2004); see also Bhaumik et al. (2006) and Powers et al. (2011). This approach relies on a system of weights associated with the contribution of each covariate to $E$ and $C$. These weights are obtained by approximating the value of the average of function $\overline{F(X \beta)}$ with the value of the function evaluated at the average values of the elements of $X, F(\bar{X} \beta)$, and applying a first-order Taylor linearization of Eq. (4) around $\bar{X}^{1} \beta^{1}$ and $\bar{X}^{0} \beta^{0}$ to get the individual characteristics and coefficients effects, respectively. The weights derived in Yun (2004) for $E$ are given by:

$$
W_{\Delta X}^{g}=\frac{\left(\bar{X}_{g}^{1}-\bar{X}_{g}^{0}\right) \beta_{g}^{1}}{\left(\bar{X}^{1}-\bar{X}^{0}\right) \beta^{1}}, \quad \sum_{g=1}^{G} W_{\Delta X}^{g}=1,
$$

while the weights for $C$ are:

$$
W_{\Delta \beta}^{g}=\frac{\left(\beta_{g}^{1}-\beta_{g}^{0}\right) \bar{X}_{g}^{0}}{\left(\beta^{1}-\beta^{0}\right) \bar{X}^{0}}, \quad \sum_{g=1}^{G} W_{\Delta \beta}^{g}=1 .
$$

The overall change in unhappiness rate over time can be expressed as a weighted sum of individual contributions of each covariate in the following way:

$$
U H^{1}-U H^{0}=E+C=\sum_{g=1}^{G} W_{\Delta X}^{g} E+\sum_{g=1}^{G} W_{\Delta \beta}^{g} C=\sum_{g=1}^{G} E_{k}+\sum_{g=1}^{G} C_{k} .
$$

The weights (5) and (6) are equal to the proportional contribution of each covariate to the aggregate effects $E$ and $C$ obtained in a linear regression framework. They are thus easy to interpret and straightforward to compute as well. Moreover, the approach of Yun (2004) avoids the path dependency problem of other decomposition methods based on nonlinear models, which appears when the values of characteristics and coefficients associated with one period of analysis need to be sequentially replaced with the corresponding values

\footnotetext{
12 Alternatively, the reference and comparison period can be reversed or a three-way decomposition can be performed, which specifies additionally an interaction term accounting for differences in endowments and coefficients existing simultaneously between the two time periods. We have performed decompositions using period 1 as the reference period (the results are available upon request). Most of the results are robust to this change.
} 
from the other period of analysis. The detailed decomposition using weights (5) and (6) is invariant to the order of inclusion of variables into the decomposition. Another advantage of the approach is that it is invariant to the scale of covariates. It is also convenient that the decomposition (7) reduces to the Oaxaca-Blinder methodology, if the linear regression model is applied. Finally, the standard errors for all elements of the decomposition can be easily computed using the delta method (Powers et al. 2011).

A very well-known problem related to the detailed decomposition like (7) is the fact that the individual coefficients effects are not invariant to the choice of the reference (or omitted) category, when categorical variables (with more than two categories) are used as elements of $X$ (Yun 2005). This is due to the impossibility of distinguishing between the part of the observed difference in outcome which is captured by the difference in models' intercepts (and therefore unexplained by the decomposition) and the part attributed to differences in the coefficient of the reference category. Changing the reference category for a given variable with more than two categories will lead to a change in the sum of coefficients effects for this variable. This seems to be undesirable as the choice of the reference category is often rather arbitrary-for example in case of variables such as marital status, type of residence, ethnic group, etc. In order to overcome this problem, we use a solution proposed by Yun $(2005,2008)$. According to his proposal, the problem of identification of the coefficients for all dummy variables including the omitted category can be resolved by averaging all estimated coefficients for the dummy variables while permuting the reference groups. The coefficients for the dummy variables can be then expressed as deviations from the coefficients' overall mean. Specifically, for a categorical variable with $L$ levels, the estimated coefficients $\beta_{0}, \ldots, \beta_{L}$ with $\beta_{0}$ being the intercept and $\beta_{1}$ constrained to zero are transformed to $\tilde{\beta}_{0}, \ldots, \tilde{\beta}_{L}$ by imposing the restriction $\sum_{i=1}^{L} \tilde{\beta}_{i}=0$. The normalized coefficients are defined as:

$$
\tilde{\beta}_{0}=\beta_{0}+\sum_{i=1}^{L} \frac{\beta_{i}}{L}, \tilde{\beta}_{j}=\beta_{j}-\sum_{i=1}^{L} \frac{\beta_{i}}{L}, j=1, \ldots, L .
$$

The Yun normalization given in (8) is invariant to the choice of the reference category in calculating the contribution of as set of dummy variables representing a categorical variable to the detailed coefficients effects. It has also the advantage of not affecting the computation of detailed characteristics effects and coefficients effects of continuous variables. The results of the detailed decompositions based on (8) are equal to the arithmetical average of a series of decompositions in which every category is sequentially used as the reference category. Notice that the application of the Yun's (2005) normalization to the decomposition (7) leads to the identification of the detailed characteristics and coefficients effects for each category of a categorical variable, including the original reference category.

The decomposition of changes in unhappiness (7) is based on simple regression models (1) and provides information about how a given factor determining individual happiness accounts for unhappiness changes while controlling for other factors. It must be stressed here, however, that the simple specification (1) precludes treating the established correlation between unhappiness changes and its covariates as a causal relationship. ${ }^{13}$ The reverse

\footnotetext{
${ }^{13}$ Litchfield et al. (2012) show that the assumptions of the simple ordered probit or logit models often used in modelling categorical life satisfaction are violated by the life satisfaction data for Albania. Ferrer-i-Carbonell and Frijters (2004) argue that modelling life satisfaction with cross-sectional data, which does not take into account unobserved heterogeneity may lead to incorrect inferences about the determinants of happiness.
} 
causality from unhappiness to household and individual characteristics such as income poverty or unemployment cannot be excluded. Therefore, we treat our results as showing only correlations, not causality. Still, using the decomposition (7) allows to separate the "contributions" to changes in unhappiness of individual happiness-affecting factors, while other factors are also controlled for.

The decomposition (7) proposed by Yun (2005) has been applied recently not only in the context of accounting for differences in income poverty (see, e.g., Gradín 2009, 2012), but also in research on health. Powers (2016) has used it to investigate the differences in infant mortality rates between older non-Hispanic whites and Mexican-origin women in Mexico. Zhang et al. (2015) have decomposed the gender gap in self-rated health in China. Finally, Taber et al. (2016) used the decomposition to study the race and gender differences in adolescent obesity in the United States.

\section{Data and Descriptive Findings}

\subsection{The Russian Longitudinal Monitoring Survey (RLMS)}

For Russia, we use data from the Russian Longitudinal Monitoring Survey (RLMS), which is a nationally representative panel survey designed to measure the effects of the economic transformation on the well-being of Russians. The survey started in 1992, but its Phase 1 conducted between 1992 and 1994 is considered unreliable. Phase 2 was conducted annually between 1994 and 2014. The initial sample was 4000 households chosen using a multistage sample design with 98 primary sampling units. More information about the survey and its design is provided by Kozyreva et al. (2016). ${ }^{14}$ The data from the RLMS have been extensively used in investigating happiness in Russia (see, e.g., Graham et al. 2004; Senik 2004; Frijters et al. 2006). In our application, we use the cross-sectional version of the RLMS and apply cross-sectional weights in all calculations. For our decomposition analyses, we use samples for 1994 and 2014 and restrict them to individuals aged 18-64. This gives us 6545 observations in 1994 and 7794 observations in 2014.

The RLMS includes the following question about self-reported life satisfaction: "To what extend are you satisfied with your life in general at the present time?", with answers coded on a five-point ordinal scale: fully satisfied (assigned numerical value of 4), rather satisfied (3), neither satisfied or dissatisfied (2), less than satisfied (1) and, not at all satisfied (0). The distribution of respondents falling in each happiness category between 1994 and 2014 is shown on Fig. 1. As the justification of the appropriate unhappiness cut-off is beyond the scope of this paper, we perform our analysis for Russia for each of the three lowest happiness cut-offs in the RLMS ("not at all satisfied", "less than satisfied", "neither satisfied or dissatisfied").

In our decomposition analyses identifying correlates of unhappiness, we use the standard variables applied previously in the studies searching for determinants of happiness in Eastern Europe (see review in Sect. 2.2). We therefore include variables related to gender, age, education, monthly equivalized real income level, self-rated health, obesity and overweight status, labour market characteristics, place of residence, marital status, parenthood,

\footnotetext{
${ }^{14}$ See also Kozyreva and Sabirianova Peter (2015) and the Special Issue of Economics in Transition (vol. 23(2), 2015) on Economic Change in Russia: Twenty Years of the Russian Longitudinal Monitoring Survey.
} 
nationality and wealth ("having savings" and "owing house"-dummy variables equal to 1 if the respondent, respectively, has savings and owns her housing). ${ }^{15}$ In order to account for income inequality on the level of individual respondent, we follow Becchetti et al. (2014) in constructing two dummy variables describing if the respondent is poor (income less than $60 \%$ of the overall median income in the sample) or rich (income higher than $200 \%$ of the overall median income). Further, the impact of relative income is considered through computing median income of the reference group (defined as a group of individuals with the same gender, age class and education category) and using it to construct variables describing states of being relatively poor and relatively rich. "Relatively poor" is defined as having income lower than $60 \%$ of the reference income, while "relatively rich" as having income greater than $200 \%$ of the reference income. We also include regional dummies in all decomposition analyses.

The descriptive statistics for all variables used in the decomposition of changes in unhappiness in Russia are presented in Table 1.

\subsection{The Polish Social Diagnosis Survey}

The data for Poland come from the Social Diagnosis (SD) project, which is a nationally representative panel survey collecting information on objective and subjective determinants of quality of life in Poland (Czapiński and Panek 2015). ${ }^{16}$ The first round of the SD was conducted in 2000, while the subsequent rounds took place every second year starting from 2003. The initial sample was 3005 households with 6614 adult respondents. A big refreshment sample was added to the survey in 2009- the sample size in this year increased to 12,380 households with 26,243 adult respondents. The SD uses a two-stage stratified sampling method with stratification by voivodships and the class of the place of residence (see Czapiński and Panek 2015 for more details). For the purpose of estimating trends in unhappiness, we have used also a predecessor survey for the SD, the Polish General Survey of Quality of Life (PGSQL) (Czapiński 1998), which had a very similar sample design to the SD. However, in our decomposition exercises we use only data from the SD survey (for the years 2000 and 2015). The sample is limited to respondents aged 18-64, which gives 5075 observations for 2000 and 14,709 observations for 2015 . We apply crosssectional weights supplied in the SD in all our estimations.

The happiness question in the SD was adapted from the WVS and takes the form: "Taking everything into account, how would you assess your life-would you say that you are..." with responses coded on a four-point scale: very happy, quite happy, not very happy, unhappy. ${ }^{17}$ Unfortunately, in the first wave of the SD and in several waves of the PGSQL the two lowest happiness categories (not very happy, unhappy) were merged into one (not very happy). Therefore, in order to use a consistent measure of happiness we have merged the two lowest happiness categories also for all other waves of the SD survey and

\footnotetext{
15 Real absolute income is equivalized using the square root equivalence scale (i.e. square root of the number of household members).

16 Baranowska and Matysiak (2011) have used data from the SD survey to study the effect of parenthood on happiness in Poland. Michon (2014) investigated gender-related happiness inequality exploiting the SD data.

17 The SD includes also a life satisfaction question. We have performed our analyses also using the life satisfaction variable and obtained results very similar to those established for the happiness variable. See also Chrostek (2016) for a comparison of the happiness and life satisfaction variables in the SD.
} 

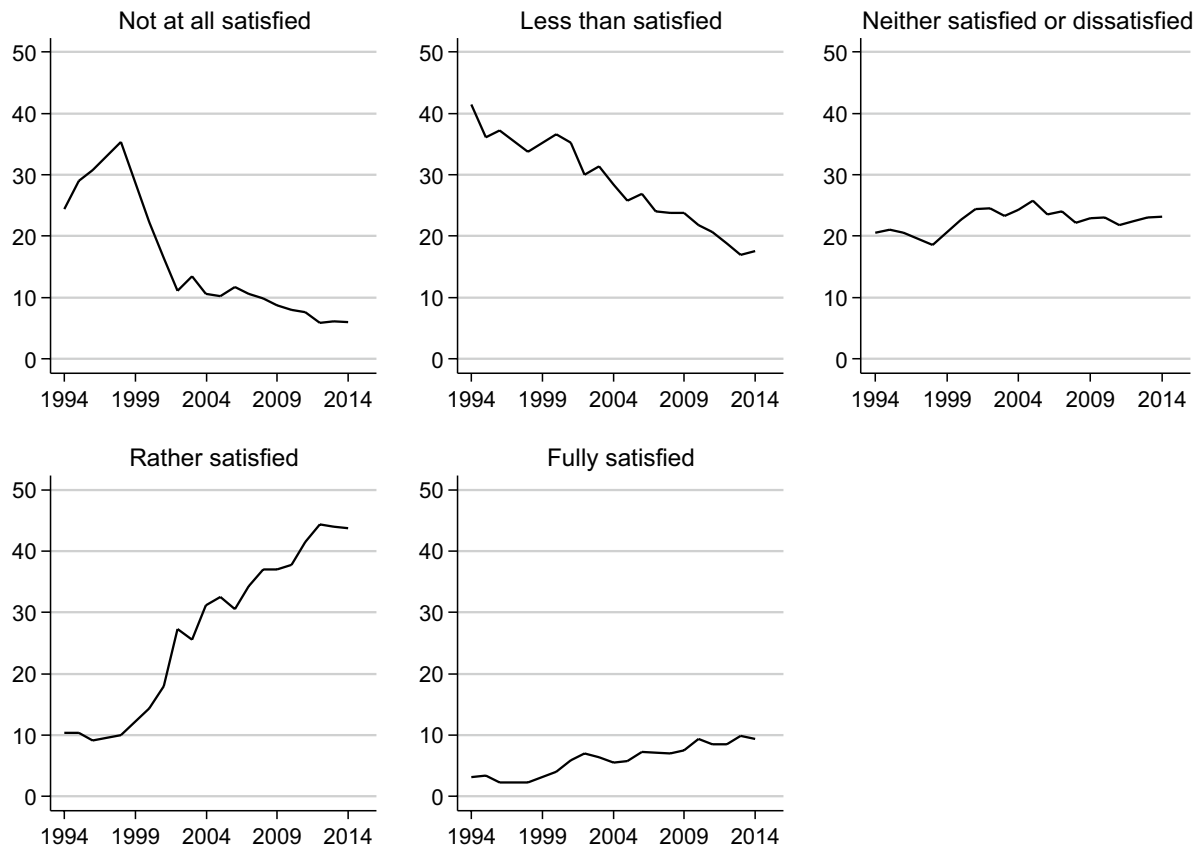

Fig. 1 Percentages of population reporting each happiness category, Russia, 1994-2014. Note: Life satisfaction question: "To what extent are you satisfied with your life at the present time?" Source: own computation using the RLMS data

use a happiness variable with 3-point response scale: very happy, quite happy, not very happy or unhappy. The obvious candidate for unhappiness threshold is therefore the lowest happiness category-not very happy or unhappy. The distribution of respondents falling in each happiness category for Poland between 1991 and 2015 is shown on Fig. 2.

For Poland, we use a similar set of covariates as for Russia. However, we do not have information about obesity or overweight and the ownership of respondent's housing. The SD survey allows to add variables related to religiosity (intensity of participation in religious services) and social capital (number of friends and dummy variable taking value of one if the respondent is doing community work). ${ }^{18}$ Regional dummies were used in all decomposition analyses for Poland.

The descriptive statistics for all variables used in the decomposition of changes in unhappiness in Poland between 2000 and 2015 are presented in Table 2.

\subsection{Trends in Mean Happiness and Unhappiness}

Figure 3 traces the evolution of the log real GDP per capita and mean happiness for both countries, with changes normalized to the initial year of analysis (1994 for Russia and 1991

\footnotetext{
18 We were unable to construct consistent over time variables related to religiosity and social capital in case of the RLMS.
} 
Table 1 Descriptive statistics for Russia, 1994 and 2014. Source: RLMS

\begin{tabular}{|c|c|c|c|c|}
\hline & \multicolumn{2}{|l|}{1994} & \multicolumn{2}{|l|}{2014} \\
\hline & Mean & $\mathrm{SD}$ & Mean & SD \\
\hline$P(k=1)$ & 0.244 & 0.430 & 0.060 & 0.238 \\
\hline$P(k=2)$ & 0.659 & 0.474 & 0.236 & 0.425 \\
\hline$P(k=3)$ & 0.865 & 0.342 & 0.468 & 0.499 \\
\hline Female & 0.521 & 0.500 & 0.524 & 0.499 \\
\hline Age 18-24 & 0.163 & 0.369 & 0.144 & 0.351 \\
\hline Age $25-34$ & 0.243 & 0.429 & 0.241 & 0.428 \\
\hline Age $35-44$ & 0.241 & 0.428 & 0.208 & 0.406 \\
\hline Age $45-54$ & 0.171 & 0.377 & 0.209 & 0.406 \\
\hline Age 55-64 & 0.182 & 0.386 & 0.198 & 0.399 \\
\hline Low education & 0.226 & 0.418 & 0.053 & 0.223 \\
\hline Medium education & 0.593 & 0.491 & 0.687 & 0.464 \\
\hline High education & 0.181 & 0.385 & 0.260 & 0.439 \\
\hline Monthly real equivalized income level (in RUB) & 5092.1 & 7422.5 & $10,343.8$ & 7079.5 \\
\hline Poor & 0.236 & 0.425 & 0.182 & 0.386 \\
\hline Rich & 0.170 & 0.376 & 0.096 & 0.295 \\
\hline Relatively poor & 0.230 & 0.421 & 0.170 & 0.375 \\
\hline Relatively rich & 0.167 & 0.373 & 0.094 & 0.292 \\
\hline Bad self-rated health & 0.125 & 0.331 & 0.071 & 0.256 \\
\hline Good self-rated health & 0.280 & 0.449 & 0.434 & 0.496 \\
\hline Obese (based on self-assessment) & 0.196 & 0.397 & 0.232 & 0.422 \\
\hline Overweight (based on self-assessment) & 0.298 & 0.458 & 0.303 & 0.460 \\
\hline Employed & 0.694 & 0.461 & 0.689 & 0.463 \\
\hline Unemployed & 0.088 & 0.283 & 0.073 & 0.260 \\
\hline Retired & 0.103 & 0.305 & 0.103 & 0.304 \\
\hline Inactive & 0.096 & 0.295 & 0.118 & 0.322 \\
\hline Disabled & 0.021 & 0.143 & 0.019 & 0.136 \\
\hline Living in Moscow or Saint Petersburg & 0.102 & 0.302 & 0.111 & 0.315 \\
\hline Living in rural area & 0.247 & 0.431 & 0.252 & 0.434 \\
\hline Russian nationality (self-assessed) & 0.834 & 0.372 & 0.846 & 0.361 \\
\hline Married & 0.719 & 0.450 & 0.537 & 0.499 \\
\hline No longer married & 0.138 & 0.345 & 0.198 & 0.399 \\
\hline Having children & 0.709 & 0.454 & 0.720 & 0.449 \\
\hline Having savings & 0.100 & 0.300 & 0.124 & 0.330 \\
\hline Owing house & 0.565 & 0.496 & 0.828 & 0.378 \\
\hline$N$ & 6546 & & 7794 & \\
\hline
\end{tabular}

SD denotes the standard deviation. All statistics are weighted using cross-sectional survey weights. $\mathrm{P}(\mathrm{k}=i)$ is the proportion of population reporting happiness equal or less to $i$. For Poland, $i=1$ corresponds to respondents reporting that they are not very happy or unhappy. In case of Russia, $i=1$ denotes category of respondents saying that they are not at all satisfied with their life, $i=2$-category of respondents who are at most less than satisfied with their life, and $i=3$-respondents who are at most neither satisfied or dissatisfied with their life

See Sect. 4.1 and Table 7 in the "Appendix" for definitions of other variables 

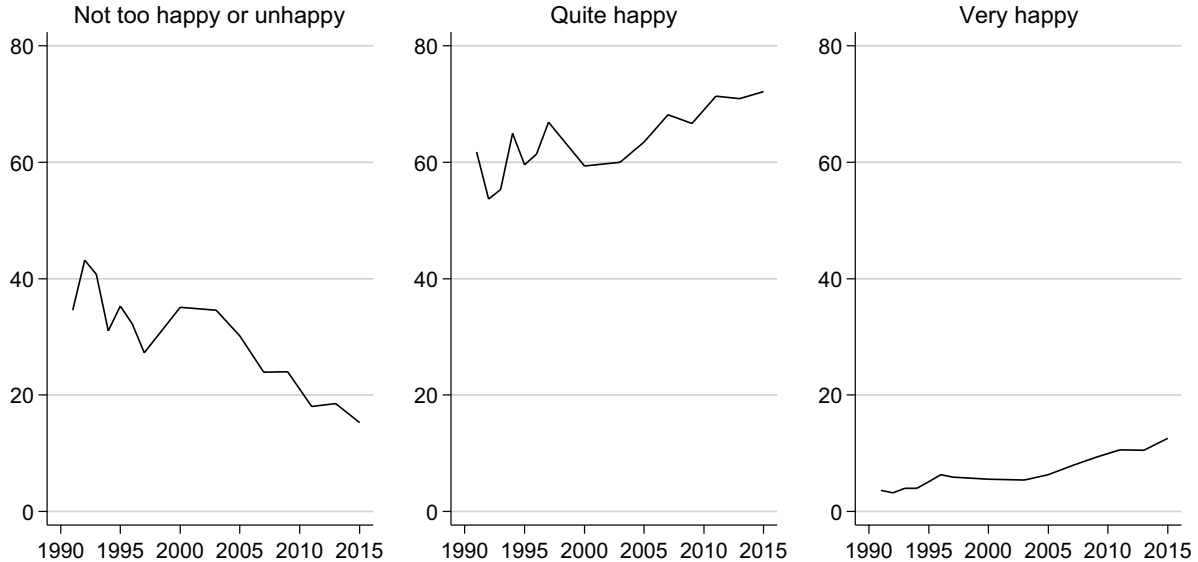

Fig. 2 Percentages of population reporting each happiness category, Poland, 1991-2015. Note: Happiness question: "Taking everything into account, how would you assess your life—would you say that you are ..." Source: Own computation using the Social Diagnosis data

for Poland). ${ }^{19}$ For Russia, the real GDP per capita was declining for most of the 1990s and started to grow consistently only since 1998. Log GDP per capita increased by about $7.5 \%$ over 1994-2014, while the GDP per capita by about $86 \%$. Mean happiness grew in the same period by $47 \%$, although until 1998 it was falling more rapidly than the log GDP per capita. The figure suggests, similarly to Frijters et al. (2006) and Guriev and Zhuravskaya (2009), that there is no evidence for the Easterlin paradox for Russia, at least if the period 1994-2014 is considered.

The log GDP per capita for Poland increased by about $10 \%$ over 1991-2015, while the GDP per capita by $165 \%$. Mean happiness grew in the same period by $13.4 \%$, although between 1991 and 2003 it followed the up and down pattern despite continuous growth of the GDP. This behaviour of mean happiness can be explained by noting that despite positive economic growth in Poland after 1992, unemployment rate was fluctuating between 10 and $20 \%$ over $1992-2002$ (for example it grew from $10.7 \%$ in 1998 to $19.9 \%$ in 2002) (see also Angelescu 2008). Figure 3 does not give support for the existence of the Easterlin paradox in Poland as over the period under study mean happiness has in general followed growth in the GDP per capita.

Figure 4 uses comparable data from the WVS to show the differences in mean happiness and in the unhappiness rates between Eastern European countries and the West. The West is represented by average of estimates for Sweden and Switzerland-countries that consistently rank among the happiest ten countries in the world. For example, Switzerland ranks second, while Sweden is tenth happiest country in the recent World Happiness Report 2016 (Helliwell et al. 2016). The comparison of mean happiness

\footnotetext{
19 The strict comparability of happiness and unhappiness trends between Poland and Russia is limited by the fact that for Russia we are in fact using a life satisfaction measure (the only subjective well-being measure available in the RLMS). I thank the referee for pointing this out. However, Clark (2016) shows that happiness and life satisfaction are strongly correlated in a sample of 25 European countries (the correlation coefficient of 0.71), while the determinants of happiness and life satisfaction are almost perfectly correlated with the correlation coefficient equal to 0.95 .
} 
Table 2 Descriptive statistics for Poland, 1991, 2000 and 2015. Source: Social Diagnosis

\begin{tabular}{|c|c|c|c|c|c|c|}
\hline & \multicolumn{2}{|l|}{1991} & \multicolumn{2}{|l|}{2000} & \multicolumn{2}{|l|}{2015} \\
\hline & Mean & SD & Mean & SD & Mean & SD \\
\hline$P(k=1)$ & 0.345 & 0.475 & 0.350 & 0.477 & 0.153 & 0.360 \\
\hline Female & 0.548 & 0.498 & 0.528 & 0.499 & 0.512 & 0.500 \\
\hline Age $18-24$ & 0.095 & 0.294 & 0.148 & 0.355 & 0.120 & 0.325 \\
\hline Age $25-34$ & 0.224 & 0.417 & 0.223 & 0.416 & 0.235 & 0.424 \\
\hline Age $35-44$ & 0.286 & 0.452 & 0.230 & 0.421 & 0.226 & 0.418 \\
\hline Age $45-54$ & 0.188 & 0.391 & 0.249 & 0.432 & 0.194 & 0.395 \\
\hline Age 55-64 & 0.207 & 0.405 & 0.151 & 0.358 & 0.225 & 0.418 \\
\hline Low education & 0.638 & 0.481 & 0.520 & 0.500 & 0.400 & 0.490 \\
\hline Medium education & 0.290 & 0.454 & 0.375 & 0.484 & 0.351 & 0.477 \\
\hline High education & 0.072 & 0.259 & 0.106 & 0.307 & 0.249 & 0.433 \\
\hline Monthly real equivalized income level (in PLN) & 1352.5 & 672.5 & 1306.6 & 759.0 & 2440.1 & 1528.3 \\
\hline Poor & 0.123 & 0.328 & 0.168 & 0.374 & 0.175 & 0.380 \\
\hline Rich & 0.054 & 0.227 & 0.072 & 0.258 & 0.069 & 0.253 \\
\hline Relatively poor & 0.109 & 0.312 & 0.138 & 0.345 & 0.139 & 0.346 \\
\hline Relatively rich & 0.042 & 0.201 & 0.053 & 0.223 & 0.059 & 0.236 \\
\hline Bad self-rated health & 0.188 & 0.391 & 0.197 & 0.398 & 0.094 & 0.292 \\
\hline Good self-rated health & 0.384 & 0.487 & 0.406 & 0.491 & 0.500 & 0.500 \\
\hline Employed & 0.637 & 0.481 & 0.545 & 0.498 & 0.648 & 0.478 \\
\hline Unemployed & 0.061 & 0.240 & 0.113 & 0.316 & 0.072 & 0.259 \\
\hline Retired & 0.105 & 0.307 & 0.084 & 0.277 & 0.068 & 0.251 \\
\hline Inactive & 0.089 & 0.285 & 0.143 & 0.350 & 0.151 & 0.358 \\
\hline Disabled & 0.107 & 0.309 & 0.116 & 0.321 & 0.060 & 0.238 \\
\hline Living in large cities $(100,000+$ inhabitants $)$ & 0.292 & 0.455 & 0.295 & 0.456 & 0.285 & 0.452 \\
\hline Living in big cities (500,000 + inhabitants) & - & - & 0.091 & 0.288 & 0.112 & 0.315 \\
\hline Living in rural area & 0.397 & 0.489 & 0.360 & 0.480 & 0.406 & 0.491 \\
\hline Farmer & 0.094 & 0.292 & 0.066 & 0.249 & 0.066 & 0.247 \\
\hline Married & 0.781 & 0.413 & 0.692 & 0.462 & 0.606 & 0.489 \\
\hline No longer married & 0.091 & 0.287 & 0.077 & 0.267 & 0.085 & 0.280 \\
\hline Having children & 0.835 & 0.371 & 0.714 & 0.452 & 0.679 & 0.467 \\
\hline Number of friends & 7.047 & 6.572 & 5.101 & 5.011 & 6.247 & 6.542 \\
\hline Not taking part in religious services & 0.047 & 0.212 & 0.275 & 0.446 & 0.348 & 0.476 \\
\hline Religious services less than 4 times per month & 0.330 & 0.470 & 0.252 & 0.434 & 0.260 & 0.439 \\
\hline Religious services 4 times per month & 0.448 & 0.497 & 0.342 & 0.475 & 0.299 & 0.458 \\
\hline Religious services more than 4 times per month & 0.175 & 0.380 & 0.131 & 0.337 & 0.093 & 0.291 \\
\hline Having savings & - & - & 0.218 & 0.413 & 0.453 & 0.498 \\
\hline Doing community work & - & - & 0.087 & 0.281 & 0.163 & 0.370 \\
\hline$N$ & 3160 & & 5075 & & 14,709 & \\
\hline
\end{tabular}

SD denotes the standard deviation. All statistics are weighted using cross-sectional survey weights. See Sects. 4.1-4.2 and Table 7 in the "Appendix" for definitions of variables 

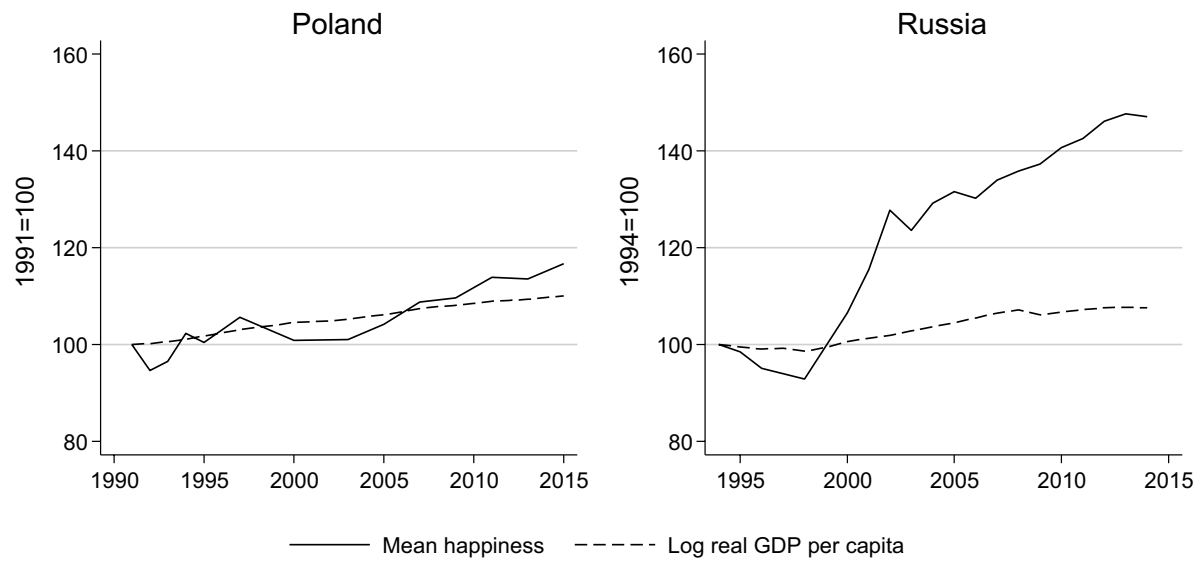

Fig. 3 Changes in mean happiness and log real GDP per capita, normalized to the initial year of analysis, Poland (1991-2015) and Russia (1994-2014) Source: own computation. Happiness data are taken from the RLMS (Russia) and the SD survey (Poland). Real GDP per capita data come from the IMF and the World Bank World Development Indicators
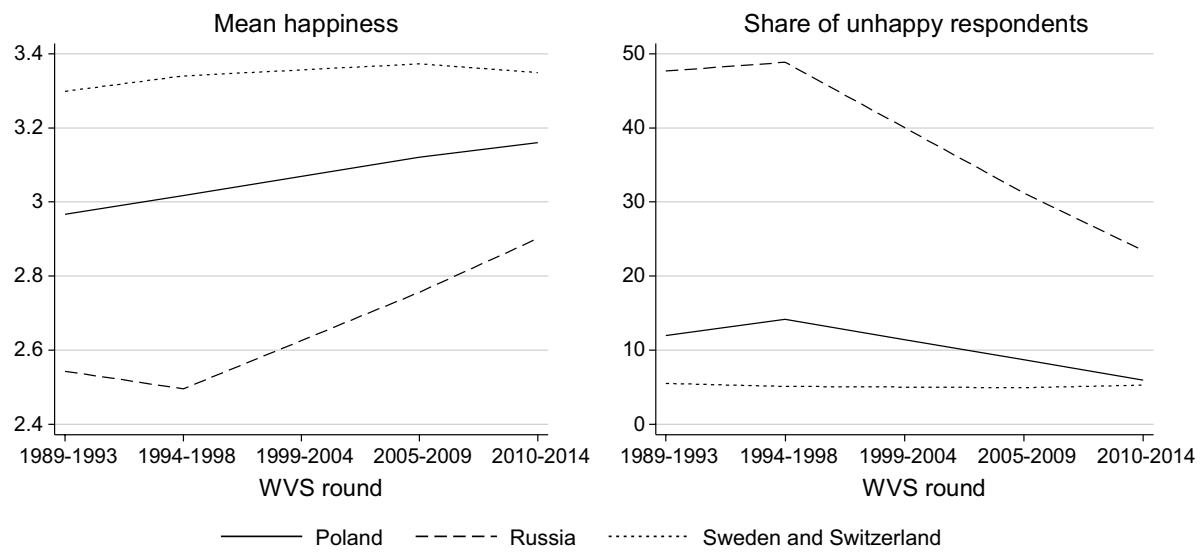

Fig. 4 Mean happiness (left panel) and share of unhappy respondents (right panel), Poland and Russia versus Sweden and Switzerland combined, 1989-2014. Note: Happiness question is: "Taking all things together, would you say you are" with answers on a 4-point scale: very happy, quite happy, not very happy, not at all happy. Share of unhappy respondents shown on the right panel is defined as the proportion of respondents reporting that they are not very happy or not at all happy Source: World Values Survey

shows that the happiness gap between Eastern and Western Europe described, among others, by Guriev and Zhuravskaya (2009) and Djankov et al. (2016) is slowly closing for Poland and, since the mid-to-late 1990s somewhat faster for Russia. However, the gap for Russia is still slightly more than twice the gap for Poland. The right panel of Fig. 4 traces the evolution of the proportion of unhappy people in the compared countries. According to the WVS data, the unhappiness rate in Poland was slightly growing in the early 1990s, but since the mid-1990s is fell considerably reaching Western levels 

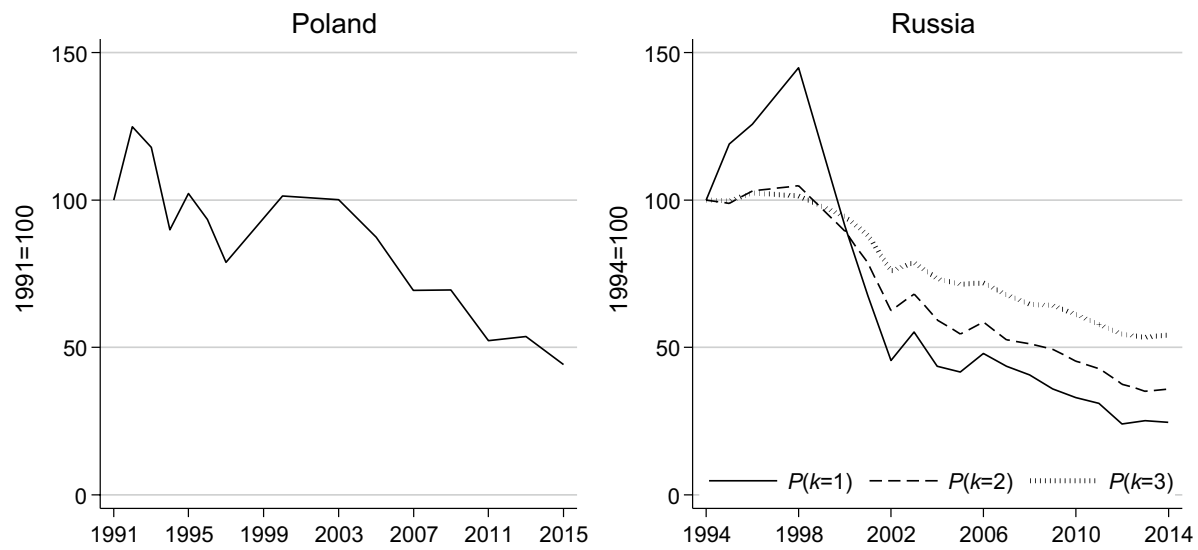

Fig. 5 Changes in unhappiness, normalized to the initial year, Poland (1991-2015) and Russia (19942014). Note: The figure for Poland shows only the $P(k=1)$ measure Source: own computation. Happiness data are taken from the RLMS (Russia) and the SD survey (Poland)

in early 2010s. A similar pattern of change can be observed for Russia, but the reduced unhappiness rate in early 2010s is still about 4 times higher than in Poland.

Trends in unhappiness rates for Poland and Russia computed using, respectively, the SD survey and the RLMS are shown on Fig. 5. In case of Poland, we observe an initial spike in unhappiness over 1991-1992, followed by some fluctuations up to 2003 and a steady decline in unhappiness after 2003. Broadly similar trends for Poland have been found by Bjørnskov and Ming-Chang (2015, Figure 2) based on the WVS data. For Russia, the behaviour of unhappiness rates, especially $P(k=2)$ and $P(k=3)$, is pretty similar to that of Poland. In case of the unhappiness rate with the lowest unhappiness threshold, $P(k=1)$, we observe a huge spike between 1994 and 1998, followed by a radical decline up to 2002 and a somewhat slower decrease up to 2014.

Tables 3, 4 provide estimates of unhappiness rates for Poland and Russia, together with their estimated standard errors. ${ }^{20}$ All declines in unhappiness rates for the periods under study (2000-2015 for Poland and 1994-2014 for Russia) are statistically significant. It must be also stressed here that these declines are quantitatively huge-the unhappiness rate has fallen by $56 \%$ for Poland and within 46-75\% range for Russia. These estimates suggest that from the point of view of progress in minimizing misery both countries have done extremely well. On the other hand, there is still about $15 \%$ of Poles, who consider themselves unhappy in 2015. The proportion of unhappy Russians in 2014 depends on the unhappiness threshold assumed and varies from as little as $6 \%(k=1)$ to as much as $47 \%$ $(k=3)$.

\footnotetext{
20 The standard errors were computed using asymptotic variance formula developed by Kakwani for income poverty measures (Kakwani 1993).
} 


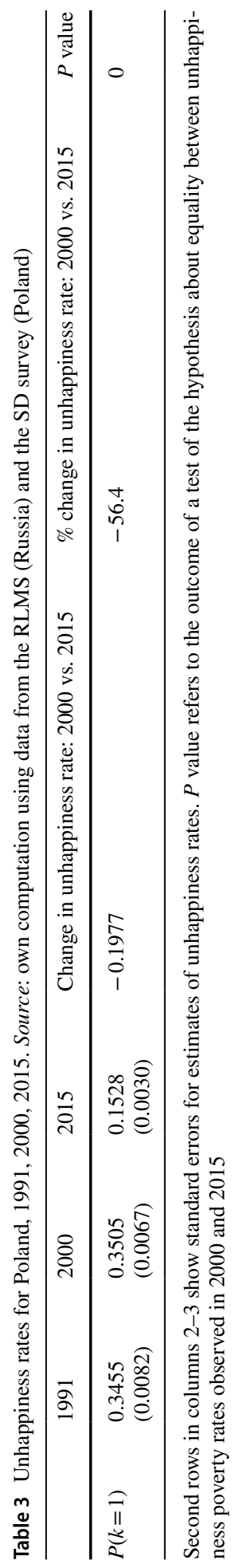


Table 4 Unhappiness rates for Russia. Source: own computation using data from the RLMS (Russia) and the SD survey (Poland)

\begin{tabular}{llllll}
\hline & 1994 & 2014 & $\begin{array}{l}\text { Change in unhappi- } \\
\text { ness rate }\end{array}$ & $\begin{array}{l}\text { \% Change in unhappi- } \\
\text { ness rate }\end{array}$ \\
\hline$P(k=1)$ & $\begin{array}{l}0.2442 \\
(0.0053)\end{array}$ & $\begin{array}{l}0.0602 \\
(0.0027)\end{array}$ & -0.1840 & -75.4 & 0 \\
$P(k=2)$ & $\begin{array}{l}0.6588 \\
(0.0059)\end{array}$ & $\begin{array}{l}0.2365 \\
(0.0048)\end{array}$ & -0.4223 & -64.1 & 0 \\
$P(k=3)$ & 0.8649 & 0.4682 & -0.3967 & -45.9 & 0 \\
& $(0.0042)$ & $(0.0057)$ & & & \\
\hline
\end{tabular}

Second rows in columns 2-3 show standard errors for estimates of unhappiness rates. $P$ value refers to the outcome of a test of the hypothesis about equality between unhappiness poverty rates observed in 1994 and 2014

\section{Decomposition of Over Time Changes in Unhappiness Rates}

We now turn to presenting and discussing the results of decomposing changes in unhappiness rates over time. The results of logit regressions for unhappiness in each period are presented in Tables 8 (Poland) and 9 (Russia) in the "Appendix". In case of Poland (observed in 2000 and 2015), we observe that the probability of being unhappy is greater for older age groups (aged 45-54 and 55-64), respondents with low education, bad self-reported health, unemployed, inactive, no longer married, and not taking part in religious services or taking part less intensively in those services. On the other hand, younger respondents are much less often unhappy as well as those with good health, married, having greater number of friends and having savings. Income level plays a protecting role against unhappiness. Being poor was not associated with unhappiness in a statistically significant way in 1991 and 2000, but it has become positively related to unhappiness in 2015. A surprising result is that being relatively rich (rich with respect to the reference group) is positively related to unhappiness in 2015. Most of these results are qualitatively consistent with the previous literature on the correlates of happiness in transition countries (Hayo 2007; Sanfey and Teskoz 2007; Selezneva 2011, 2016), as well as with the Lelkes' (2013) results concerning the correlates of unhappiness obtained for a sample of 29 European countries.

The logit regressions for Russia (Table 9 in the "Appendix") show that in both periods under study and for all three unhappiness measures younger people (especially the 18-24 age group) were less unhappy than others, as well as those with high level of education, with good self-rated health, married and having savings. Bad self-rated health and unemployment have significant positive relationship with unhappiness. Similarly to Poland, the absolute income level is negatively associated with the probability of being unhappy. Being poor is positively related to unhappiness, but the effect is not always statistically significant. Being rich had a protective role against unhappiness in 1994, but not in 2014. For the $P(k=1)$ measure, being relatively rich seems to have a strong negative effect for the probability of unhappiness. However, the effect disappears for unhappiness measures with higher unhappiness thresholds. Obesity is negatively related to unhappiness for two unhappiness measures in 1994, but not in 2014. On the other hand, being overweight has an 
unhappiness-protecting effect for two measures of unhappiness in 2014, but not in 1994 . It seems also that the significance of inactivity and disability for unhappiness has changed between 1994 and 2014 - these characteristics were rather insignificant in 1994, but have become very significant correlates of unhappiness in 2014. There was also a significant penalty for women with respect to the probability of unhappiness in 1994, which disappeared two decades later.

The results of the decomposition analysis for unhappiness change in Poland are reported in Table 5. The overall change in unhappiness is equal to $-19.7 \%$ points. Most of it is accounted for by the aggregate coefficients effect -14.2 (or $72.3 \%$ of the overall change in unhappiness). Aggregate characteristics (endowments) effect contributes $27.7 \%$ to the overall unhappiness change. The coefficient effect for the constant, which represents the correlates of unhappiness unaccounted for in our models-omitted socio-economic variables, psychological or biological factors-is equal to $83 \%$ of the overall fall in unhappiness. Negative (positive) values for an estimate of a given endowment or coefficient effect mean that the factor contributed to the decrease (increase) in unhappiness over time.

Among the significant individual endowment effects, we find that the growth in real income level accounts for about $14 \%$ of the overall unhappiness decline. At the same time, the return to income as an unhappiness-protecting factor has fallen over 2000-2015 (see Table 8 in the "Appendix"). In consequence, the coefficient effect for income level is unhappiness-increasing. In fact, since the coefficient effect for income level was higher $(-28.1 \%$ of the total unhappiness fall) than the endowment effect $(14.2 \%)$, the total contribution of income to unhappiness reduction is negative $(-13.9 \%)$, that is unhappinessincreasing. This means that the benefits for unhappiness reduction from almost doubling of the mean real income in Poland over 2000-2015 were outweighed by the reduced strength of income as an unhappiness-protecting factor. This may simply reflect a weakening link between income and (un)happiness in Poland as income surpassed some threshold level. After this threshold was reached, other (non-monetary) factors started to play a more significant role as determinants of unhappiness.

A similar story can be told about the role of bad self-rated health in Poland-reduction in the proportion of persons with bad health was outdone by increasing penalty for bad health. On the other hand, the endowment and coefficient effects for good self-rated health were working in the same direction - the growing proportion of Poles with good self-rated health (growth by $10 \%$ points over $2000-2015$ ) can explain in overall about $15.5 \%$ of the total happiness fall.

Other statistically significant endowment effects that were unhappiness-reducing include number of friends (2.5\% of the total happiness fall) and having savings $(3.8 \%)$. The falling proportion of married persons is associated with the increase of unhappiness $(3.4 \%$ of the unhappiness change). All these effects are relatively small.

Turning to the estimates of coefficient effects for Poland, we can see that the increasing premium for having children had a relatively big impact on unhappiness reduction $(18.6 \%$ of the total unhappiness fall). This might be explained by a turn to more family-friendly socio-economic policy in Poland after 2005 (Szelewa 2017). In this period, maternity leave was extended from 16 to 20 weeks, new paid parental leave and insurance schemes as well as child tax credits were introduced. Among other coefficient effects, return to being poor was increasing unhappiness (6.4\% of the total unhappiness change). This is associated with 
Table 5 Decomposition of changes in unhappiness rate $P(k=1)$ for Poland between 2000 and 2015: endowments $(E)$ and coefficients effects $(C)$. The total change in unhappiness rate $(U H)$ is -19.7 . Source: own computation using the Social Diagnosis data

\begin{tabular}{|c|c|c|c|c|c|c|}
\hline & \multicolumn{3}{|c|}{ Endowments effects $(E)$} & \multicolumn{3}{|c|}{ Coefficients effects $(C)$} \\
\hline & Estimate & SE & $\% E / U H$ & Estimate & SE & $\% \mathrm{C} / U H$ \\
\hline Aggregate effect & $-5.462 * * *$ & $(0.863)$ & 27.7 & $-14.249 * * *$ & $(1.144)$ & 72.3 \\
\hline Female & -0.008 & $(0.014)$ & 0.0 & 1.100 & $(0.885)$ & -5.6 \\
\hline Age 18-24 & $0.257 * * *$ & $(0.040)$ & -1.3 & -0.127 & $(0.401)$ & 0.6 \\
\hline Age $25-34$ & $-0.046 * * *$ & $(0.011)$ & 0.2 & -0.180 & $(0.396)$ & 0.9 \\
\hline Age $35-44$ & $-0.007 * *$ & $(0.003)$ & 0.0 & -0.066 & $(0.375)$ & 0.3 \\
\hline Age $45-54$ & $-0.282 * * *$ & $(0.047)$ & 1.4 & -0.138 & $(0.397)$ & 0.7 \\
\hline Age 55-64 & $0.448 * * *$ & $(0.059)$ & -2.3 & 0.378 & $(0.310)$ & -1.9 \\
\hline Low education & $-0.170 * *$ & $(0.080)$ & 0.9 & 0.087 & $(0.744)$ & -0.4 \\
\hline Medium education & -0.000 & $(0.014)$ & 0.0 & 0.571 & $(0.460)$ & -2.9 \\
\hline High education & $-0.206^{*}$ & $(0.120)$ & 1.0 & -0.179 & $(0.199)$ & 0.9 \\
\hline Real income level & $-2.802 * * *$ & $(0.872)$ & 14.2 & $5.546^{*}$ & $(3.152)$ & -28.1 \\
\hline Poor & $0.034 * * *$ & $(0.009)$ & -0.2 & $1.268 * *$ & $(0.499)$ & -6.4 \\
\hline Rich & -0.005 & $(0.010)$ & 0.0 & 0.169 & $(0.420)$ & -0.9 \\
\hline Relatively poor & -0.000 & $(0.001)$ & 0.0 & $-1.171 * * *$ & $(0.425)$ & 5.9 \\
\hline Relatively rich & $0.035 * *$ & $(0.018)$ & -0.2 & 0.450 & $(0.286)$ & -2.3 \\
\hline Bad self-rated health & $-1.241^{* * *}$ & $(0.127)$ & 6.3 & $1.429 * * *$ & $(0.402)$ & -7.2 \\
\hline Good self-rated health & $-0.966 * * *$ & $(0.088)$ & 4.9 & $-2.080 * * *$ & $(0.728)$ & 10.6 \\
\hline Employed & $-0.309 * * *$ & $(0.043)$ & 1.6 & 0.088 & $(0.233)$ & -0.4 \\
\hline Unemployed & $-0.225 * * *$ & $(0.077)$ & 1.1 & 0.478 & $(0.819)$ & -2.4 \\
\hline Retired & $0.057 * * *$ & $(0.017)$ & -0.3 & 0.019 & $(0.211)$ & -0.1 \\
\hline Inactive & $0.129 * *$ & $(0.061)$ & -0.7 & -0.368 & $(0.243)$ & 1.9 \\
\hline Disabled & 0.004 & $(0.008)$ & -0.0 & 0.182 & $(0.281)$ & -0.9 \\
\hline $\begin{array}{l}\text { Living in big cities }(500,000+\text { inhabit- } \\
\text { ants) }\end{array}$ & $-0.064 * *$ & $(0.031)$ & 0.3 & -0.025 & $(0.294)$ & 0.1 \\
\hline Living in rural area & $-0.109 * * *$ & $(0.039)$ & 0.6 & $-1.334 * *$ & $(0.634)$ & 6.8 \\
\hline Farmer & 0.000 & $(0.001)$ & -0.0 & -0.299 & $(0.209)$ & 1.5 \\
\hline Married & $0.661 * * *$ & $(0.125)$ & -3.4 & -1.044 & $(2.155)$ & 5.3 \\
\hline No longer married & $0.036 * * *$ & $(0.014)$ & -0.2 & 0.025 & $(0.290)$ & -0.1 \\
\hline Having children & $0.191 * * *$ & $(0.051)$ & -1.0 & $-3.676^{*}$ & $(1.991)$ & 18.6 \\
\hline Number of friends & $-0.492 * * *$ & $(0.119)$ & 2.5 & 0.698 & $(1.111)$ & -3.5 \\
\hline Not taking part in religious services & $0.242 * * *$ & $(0.050)$ & -1.2 & 0.117 & $(0.384)$ & -0.6 \\
\hline $\begin{array}{l}\text { Religious services less than } 4 \text { times/ } \\
\text { month }\end{array}$ & -0.006 & $(0.006)$ & 0.0 & -0.171 & $(0.344)$ & 0.9 \\
\hline Religious services 4 times per month & $0.115^{* * *}$ & $(0.029)$ & -0.6 & $-1.196 * * *$ & $(0.436)$ & 6.1 \\
\hline $\begin{array}{l}\text { Religious services more than } 4 \text { times/ } \\
\text { month }\end{array}$ & -0.004 & $(0.040)$ & 0.0 & $0.491^{*}$ & $(0.258)$ & -2.5 \\
\hline Having savings & $-0.753 * * *$ & $(0.205)$ & 3.8 & $0.798^{*}$ & $(0.416)$ & -4.0 \\
\hline Doing community work & -0.011 & $(0.085)$ & 0.1 & 0.095 & $(0.215)$ & -0.5 \\
\hline Region (aggregate effects) & 0.037 & $(0.080)$ & -0.2 & 0.147 & $(0.158)$ & -0.7 \\
\hline Constant & - & - & - & $-16.329 * * *$ & $(4.694)$ & 82.8 \\
\hline
\end{tabular}

$* * * p<0.01, * * p<0.05, * p<0.1$. Standard errors (SE) in parentheses 
Table 6 Decomposition of changes in unhappiness rate $P(k=2)$ for Russia between 1994 and 2014: endowments $(E)$ and coefficients effects $(C)$. The total change in unhappiness rate $(U H)$ is -42.2 . Source: own computation using RLMS data

\begin{tabular}{|c|c|c|c|c|c|c|}
\hline & \multicolumn{3}{|c|}{ Endowments effects $(E)$} & \multicolumn{3}{|c|}{ Coefficients effects $(C)$} \\
\hline & Estimate & SE & $\% E / U H$ & Estimate & SE & $\% \mathrm{ClUH}$ \\
\hline Aggregate effect & $-8.489 * * *$ & $(1.542)$ & 20.1 & $-33.75 * * *$ & $(1.726)$ & 79.9 \\
\hline Female & 0.000 & $(0.003)$ & -0.0 & $-1.664 *$ & $(0.97)$ & 3.9 \\
\hline Age 18-24 & $0.170 * * *$ & $(0.032)$ & -0.4 & $-0.772 *$ & $(0.451)$ & 1.8 \\
\hline Age $25-34$ & $0.004 *$ & $(0.002)$ & -0.0 & -0.635 & $(0.432)$ & 1.5 \\
\hline Age $35-44$ & $-0.090 * * *$ & $(0.033)$ & 0.2 & 0.384 & $(0.417)$ & -0.9 \\
\hline Age $45-54$ & $0.226^{* * *}$ & $(0.039)$ & -0.5 & 0.425 & $(0.325)$ & -1.0 \\
\hline Age 55-64 & $0.037 *$ & $(0.022)$ & -0.1 & 0.596 & $(0.438)$ & -1.4 \\
\hline Low education & $-0.538 * *$ & $(0.259)$ & 1.3 & 0.531 & $(0.491)$ & -1.3 \\
\hline Medium education & $0.167 * *$ & $(0.079)$ & -0.4 & -0.307 & $(0.804)$ & 0.7 \\
\hline High education & $-0.386 * * *$ & $(0.09)$ & 0.9 & -0.332 & $(0.33)$ & 0.8 \\
\hline Real income level & $-6.190 * * *$ & $(1.271)$ & 14.7 & $-6.139 * * *$ & $(1.897)$ & 14.5 \\
\hline Poor & -0.167 & $(0.12)$ & 0.4 & -0.419 & $(0.971)$ & 1.0 \\
\hline Rich & -0.370 & $(0.279)$ & 0.9 & $2.121 * *$ & $(0.962)$ & -5.0 \\
\hline Relatively poor & 0.010 & $(0.137)$ & -0.0 & 0.091 & $(0.953)$ & -0.2 \\
\hline Relatively rich & 0.015 & $(0.259)$ & -0.0 & 0.445 & $(0.909)$ & -1.1 \\
\hline Bad self-rated health & $-0.610 * * *$ & $(0.095)$ & 1.4 & 0.532 & $(0.378)$ & -1.3 \\
\hline Good self-rated health & $-1.286 * * *$ & $(0.179)$ & 3.0 & -0.761 & $(0.575)$ & 1.8 \\
\hline Obese & 0.007 & $(0.046)$ & -0.0 & 0.451 & $(0.454)$ & -1.1 \\
\hline Overweight & $-0.013 * *$ & $(0.006)$ & 0.0 & $-1.281 * *$ & $(0.614)$ & 3.0 \\
\hline Unemployed & $-0.199 * * *$ & $(0.025)$ & 0.5 & $0.679 * *$ & $(0.266)$ & -1.6 \\
\hline Employed & $0.048 * * *$ & $(0.006)$ & -0.1 & $-5.643 * * *$ & $(1.36)$ & 13.4 \\
\hline Retired & $0.003 * * *$ & $(0.001)$ & -0.0 & $-0.528^{*}$ & $(0.314)$ & 1.2 \\
\hline Disabled & -0.006 & $(0.006)$ & 0.0 & 0.029 & $(0.109)$ & -0.1 \\
\hline Inactive & $-0.068 * *$ & $(0.033)$ & 0.2 & 0.398 & $(0.262)$ & -0.9 \\
\hline Living in a big city & -0.036 & $(0.037)$ & 0.1 & 0.239 & $(0.727)$ & -0.6 \\
\hline Rural & -0.006 & $(0.009)$ & 0.0 & -0.953 & $(0.811)$ & 2.3 \\
\hline Russian nationality & 0.026 & $(0.022)$ & -0.1 & 1.308 & $(2.447)$ & -3.1 \\
\hline Married & $1.334 * * *$ & $(0.325)$ & -3.2 & -2.473 & $(2.303)$ & 5.9 \\
\hline No longer married & 0.020 & $(0.117)$ & -0.0 & 0.343 & $(0.504)$ & -0.8 \\
\hline Having children & 0.011 & $(0.019)$ & -0.0 & -0.366 & (1.988) & 0.9 \\
\hline Having savings & $-0.078 * *$ & $(0.039)$ & 0.2 & 0.259 & $(0.279)$ & -0.6 \\
\hline Own house & -0.458 & $(0.356)$ & 1.1 & -0.803 & $(1.271)$ & 1.9 \\
\hline Region (aggregate effects) & -0.068 & $(0.110)$ & 0.2 & -3.933 & $(5.231)$ & 9.3 \\
\hline Constant & - & - & - & $-15.567 *$ & $(8.124)$ & 36.9 \\
\hline
\end{tabular}

$* * * p<0.01, * * p<0.05, * p<0.1$. Standard errors (SE) in parentheses. Regional dummies included, but not shown

the fact that in 2015 income poverty has become a strong predictor of unhappiness (see Table 8 in the "Appendix"). The opposite effect is found for being poor with respect to the reference group - the return to this factor was unhappiness-reducing (5.9\% of total unhappiness fall) as being relatively poor was a significant correlate of unhappiness in 2000, but 
not in 2015. Other significant coefficient effects that reduced unhappiness include return to living in rural area (responsible for $6.8 \%$ of the total unhappiness reduction) and the premium for participating in religious services once per week $(6.1 \%)$.

Overall, our analysis suggests that observable socio-economic and demographic covariates account for the profound unhappiness reduction in Poland only to a moderate degree. The positive contribution of income level growth was outdone by income losing its significance as an unhappiness-protecting factor. The total contribution of good self-rated health accounts for $15.5 \%$ of the unhappiness fall, while increasing premium for having children for $18.6 \%$

We now turn to the results of decomposition of unhappiness changes that occurred over the last two decades in Russia. Table 6 presents results for $P(k=2)$ measure, that is unhappiness rate with unhappiness cut-off set to "less than satisfied". Results for the other two unhappiness measures, $P(k=1)$ and $P(k=3$ ), are broadly similar (see Table 10 in the "Appendix"). The relative contribution of the total characteristics vs total coefficients effect to the overall unhappiness change for Russia is similar to that for Poland. The former effect accounts for about $20 \%$ of the unhappiness decline, while the latter for about $80 \%$. However, in case of Russia the constant accounts only for about $37 \%$ of the observed unhappiness change for $P(k=2)$ and has even less explanatory power in case of the other unhappiness measures.

The single most important factor determining the fall in unhappiness in Russia is the growth of income level. Both endowment and coefficient effects for this factor are significant and similar in size $(-6.19$ and -6.14$)$. Overall, changes in income level account for $29.2 \%$ of the overall reduction in unhappiness as measured by $P(k=2)$. The size of this effect is similar to those found in case of measuring the impact of absolute income growth on average life satisfaction in Russia (Frijters et al. 2006; Guriev and Zhuravskaya 2009).

Among statistically significant individual characteristics effects, there is a small unhappiness-reducing effect of increased (by $15 \%$ points) proportion of respondents reporting good health (see Table 1), and a small unhappiness-increasing effect of largely reduced (by $18 \%$ points) proportion of married Russians. Each of these effects accounts for only about $3 \%$ of the overall unhappiness fall.

Turning now to results for coefficients effects, we note that after income the biggest role in unhappiness reduction was played by returns to being employed (13.4\% of the fall in unhappiness). Much smaller, but significant unhappiness-reducing effects were due to falling unhappiness penalty for women (see Table 8 in the "Appendix") and reduced probability of being unhappy for overweight persons. Finally, we can see also that being rich had a relatively small (5\% of the overall unhappiness reduction) unhappiness-increasing effect, which was due to a disappearing negative correlation between being rich and being unhappy (see Table 8 in the "Appendix"). This last result is even stronger (11.7\% of the total unhappiness reduction) for the unhappiness measure with the lower cut-off, $P(k=1)$. It is also worth noting that in case of the $P(k=1)$ measure, being of (self-assessed) Russian nationality was strongly increasing unhappiness (accounting for $35.3 \%$ of the overall unhappiness change). Finally, although the aggregate coefficients effect for regional dummies is not significant for the $P(k=2)$ measure, it is significant and accounts for a rather large part of the total unhappiness fall for the two other unhappiness measures studied (see Table 10 in the "Appendix"). This calls for a more research on the dynamics of happiness and unhappiness in Russia on the regional level. 
Overall, our results for Russia show that the biggest role in the great progress in unhappiness reduction was played by income growth and increasing returns to income and employment as unhappiness-protecting factors.

Methodological problems such as unobserved heterogeneity in reporting happiness and differences in happiness variable definitions do not allow us to compare directly differences in determinants of changes in unhappiness between Poland and Russia. However, we can provide a broad comparison of the major factors contributing to the spectacular unhappiness reductions observed in these countries. The main differentiating factor is the role of changes in household incomes. In Poland, the process of transformation from socialism to market economy brought at the beginning a significant decline in the average household income_-about 26\% between 1988 and 1991 (Keane and Prasad 2002)—which was, however, limited only to the initial period of the transition. Since 1992, Poland has experienced uninterrupted growth in household incomes. On the other hand, in Russia the mean real household income has dropped by about 52\% between 1994 and 1998 and recovered to the 1994 level only by $2001 .^{21}$ After the very fast growth over 2000-2008, the global financial crisis has hit Russian households rather hard (a fall in the average real household income by $12.6 \%$ over 2008-2009). The average household income returned to the 2008 level only by 2012. These developments suggest that the evolution of household incomes (both permanent and transitory income components) during the Russian transformation is characterized by much higher volatility as compared with other countries (see also Gorodnichenko et al. 2010). This may explain why there seems to be a more significant association between changes in incomes and changes in unhappiness for Russia than for Poland. The steady growth of incomes experienced in the last 25 years could provide a feeling of increasing economic security among the Poles and make more room for other (non-material) factors as more significant determinants of changes in unhappiness. ${ }^{22}$ In Russia, higher volatility of household incomes and occurrences of significant income shocks still preserve a strong relationship between changes in incomes and changes in unhappiness.

\section{Conclusions}

This paper contributes to the literature on self-rated happiness and unhappiness by investigating the microeconomic determinants of changes in unhappiness over time. We have used a detailed decomposition methodology that allows to split the overall change in unhappiness into the detailed characteristics and coefficients effects. Our analysis was performed for two important post-communist countries-Poland and Russia,

\footnotetext{
21 Own calculation using the RLMS data. See also Gorodnichenko et al. (2010).

22 Zagórski (2011) uses average happiness and average income data to suggest that the diminishing importance of income for happiness in Poland is due to the change in value systems of individuals in a direction consistent with the modernization theory (i.e. from materialist values to post-materialist values). Our analysis, based on micro data, shows that indeed the relationship between income and happiness/unhappiness in Poland has become weaker over time. However, since data on individual values are not available in the SD survey, we are unable to test whether Zagórski's hypothesis is correct.
} 
observed from the early 1990s to the mid-2010s. The results show that both countries achieved spectacular successes in unhappiness reduction. In Poland, the unhappiness rate dropped by $56 \%$, while in Russia by $46-75 \%$ depending on the unhappiness threshold chosen.

Our decomposition analyses show that unhappiness reduction in Eastern Europe was mostly driven by coefficients effects, while characteristics played a small, but a nonnegligible role. In both countries, income growth alone accounted for about $15 \%$ of the unhappiness reduction. However, in Russia this effect was doubled by growing return to income as an unhappiness-protecting factor, while in Poland income level has been losing this protecting power and in effect income played an unhappiness-increasing role. In Russia, another strong unhappiness-protecting factor was return to employment. For Poland, observable demographic and socio-economic factors explain much less of the unhappiness reduction than for Russia. However, we have found that in Poland good self-rated health and having children explained between 15 and $20 \%$ of the unhappiness reduction.

The policy implications of our analysis seem to be country-specific. In Poland, the role of policy in further reduction of unhappiness seems to be rather limited, but improvements in health and family-oriented policies could lower the unhappiness rate even more. For Russia, it seems that policies boosting income growth and employment could lead not only to better economic results, but also to some additional fall in unhappiness.

Acknowledgements I would like to thank the participants of the Economy and Society Conference (University of Łódź), 6th International Scientific Conference Quality of Life 2015 (Wrocław University of Economics) and the 2015 International Society for Quality of Life Studies (Phoenix) for helpful comments and suggestions on earlier versions the paper. Financial support of the Polish National Science Centre through Grant No. DEC-2013/09/B/HS4/01924 is gratefully acknowledged. The research leading to these results has received support under the European Commission's 7th Framework Programme (FP7/2013-2017) under Grant Agreement No. 312691, InGRID—Inclusive Growth Research Infrastructure Diffusion.

Open Access This article is distributed under the terms of the Creative Commons Attribution 4.0 International License (http://creativecommons.org/licenses/by/4.0/), which permits unrestricted use, distribution, and reproduction in any medium, provided you give appropriate credit to the original author(s) and the source, provide a link to the Creative Commons license, and indicate if changes were made.

\section{Appendix}

See Tables 7, 8, 9 and 10 . 
Table 7 Definitions of dependent and independent variables

\begin{tabular}{|c|c|}
\hline Variable & Definition \\
\hline \multicolumn{2}{|c|}{ Dependent variables } \\
\hline$P(k=1)$ & $\begin{array}{l}\text { Share of unhappy persons (with the lowest unhappiness } \\
\text { cut-off) }\end{array}$ \\
\hline$P(k=2)$ & $\begin{array}{l}\text { Share of unhappy persons (with the second lowest } \\
\text { unhappiness cut-off) }\end{array}$ \\
\hline$P(k=3)$ & $\begin{array}{l}\text { Share of unhappy persons (with the third lowest unhap- } \\
\text { piness cut-off) }\end{array}$ \\
\hline Female & Equal to 1 if the respondent is woman, 0 -if otherwise \\
\hline \multicolumn{2}{|c|}{ Independent variables } \\
\hline Age & Age in years \\
\hline Education & $\begin{array}{l}\text { Education is categorized into three levels using the Inter- } \\
\text { national Standard Classification of Education } 1997 \\
\text { (ISCED 1997): low education (pre-primary, primary } \\
\text { and lower secondary education levels or ISCED 0-2), } \\
\text { medium education (upper secondary and post-second- } \\
\text { ary non-tertiary education or ISCED 3-4), and high } \\
\text { education (tertiary education or ISCED 5-6) }\end{array}$ \\
\hline Real income level & $\begin{array}{l}\text { Monthly real equivalized income level expressed in local } \\
\text { currency (PLN or RUB) }\end{array}$ \\
\hline Poor & $\begin{array}{l}\text { Equal to } 1 \text { if respondent's income is lower than } 60 \% \text { of } \\
\text { the median income, } 0 \text { - if otherwise }\end{array}$ \\
\hline Rich & $\begin{array}{l}\text { Equal to } 1 \text { if respondent's income is higher than } 200 \% \text { of } \\
\text { the median income, } 0 \text { - if otherwise }\end{array}$ \\
\hline Relatively poor & $\begin{array}{l}\text { Equal to } 1 \text { if respondent's income is lower than } 60 \% \\
\text { of the median income of the reference group, } 0 \text {-if } \\
\text { otherwise. Reference group is defined as a group of } \\
\text { individuals with the same gender, age and education } \\
\text { category. }\end{array}$ \\
\hline Relatively rich & $\begin{array}{l}\text { Equal to } 1 \text { if respondent's income is higher than } 200 \% \\
\text { of the median income of the reference group, } 0 \text {-if } \\
\text { otherwise. }\end{array}$ \\
\hline Self-rated health & $\begin{array}{l}\text { For Russia, "good self-rated health" is defined as } \\
\text { reporting good or very good health; "bad self-rated } \\
\text { health"-reporting average, bad or very bad health. } \\
\text { For Poland, "good self-rated health" is defined as } \\
\text { being satisfied or very satisfied with own health; "bad } \\
\text { self-rated health"-being rather satisfied, rather unsat- } \\
\text { isfied, unsatisfied or very unsatisfied with own health. }\end{array}$ \\
\hline Obese & $\begin{array}{l}\text { Equal to } 1 \text { if the respondent is obese (Body Mass } \\
\text { Index } \geq 30 \text { ), } 0 \text { - if otherwise. BMI is calculated using } \\
\text { self-reported height and weight of the respondent }\end{array}$ \\
\hline Overweight & $\begin{array}{l}\text { Equal to } 1 \text { if the respondent is overweight }(30>\text { Body } \\
\text { Mass Index } \geq 25), 0-\text { if otherwise }\end{array}$ \\
\hline Employed & Equal to 1 if respondent is employed, 0 - if otherwise \\
\hline Unemployed & Equal to 1 if respondent is unemployed, 0 - if otherwise \\
\hline Retired & Equal to 1 if respondent is retired, 0 - if otherwise \\
\hline Inactive & $\begin{array}{l}\text { Equal to } 1 \text { if respondent is out of the labour force, } 0 \text { - if } \\
\text { otherwise }\end{array}$ \\
\hline Disabled & $\begin{array}{l}\text { Equal to } 1 \text { if respondent reports disability, 0-if other- } \\
\text { wise }\end{array}$ \\
\hline
\end{tabular}


Table 7 (continued)

\begin{tabular}{|c|c|}
\hline Variable & Definition \\
\hline Living in Moscow or Saint Petersburg & $\begin{array}{l}\text { Equal to } 1 \text { if respondent lives in Moscow or Saint Peters- } \\
\text { burg, } 0 \text { - if otherwise }\end{array}$ \\
\hline Living in large cities* & $\begin{array}{l}\text { Equal to } 1 \text { if respondent lives in a large city } \\
(100,000+\text { inhabitants }), 0 \text { - if otherwise }\end{array}$ \\
\hline Living in big cities* & $\begin{array}{l}\text { Equal to } 1 \text { if respondent lives in a big city } \\
(500,000+\text { inhabitants }), 0 \text { - if otherwise }\end{array}$ \\
\hline Living in rural area & $\begin{array}{l}\text { Equal to } 1 \text { if respondent lives in rural area, } 0 \text {-if other- } \\
\text { wise }\end{array}$ \\
\hline Farmer* & Equal to 1 if respondent is a farmer, 0 -if otherwise \\
\hline Russian nationality & $\begin{array}{l}\text { Equal to } 1 \text { if respondent declares Russian nationality, } \\
0 \text {-if otherwise }\end{array}$ \\
\hline Married & Equal to 1 if respondent is married, 0 -otherwise \\
\hline No longer married & $\begin{array}{l}\text { Equal to } 1 \text { if respondent is divorced, separated or wid- } \\
\text { owed, } 0 \text { - otherwise }\end{array}$ \\
\hline Having children & Equal to 1 if respondent has children, 0 -otherwise \\
\hline Having savings & $\begin{array}{l}\text { Equal to } 1 \text { if respondent reports having savings, } 0 \text { - } \\
\text { otherwise }\end{array}$ \\
\hline Owing house & Equal to 1 if respondent owns a house, 0 -otherwise \\
\hline Number of friends* & Self-reported number of friends \\
\hline Not taking part in religious services* & $\begin{array}{l}\text { Equal to } 1 \text { if respondent is not participating in religious } \\
\text { services, } 0 \text { - otherwise }\end{array}$ \\
\hline Religious services less than 4 times per month* & $\begin{array}{l}\text { Equal to } 1 \text { if respondent is participating in religious } \\
\text { services less than } 4 \text { times per month, } 0 \text { - otherwise }\end{array}$ \\
\hline Religious services 4 times per month* & $\begin{array}{l}\text { Equal to } 1 \text { if respondent is participating in religious } \\
\text { services } 4 \text { times per month, } 0 \text { - otherwise }\end{array}$ \\
\hline Religious services more than 4 times per month* & $\begin{array}{l}\text { Equal to } 1 \text { if respondent is participating in religious } \\
\text { services more than } 4 \text { times per month, } 0 \text { - otherwise }\end{array}$ \\
\hline Doing community work* & $\begin{array}{l}\text { Equal to } 1 \text { if respondent reports doing community work, } \\
0 \text { - otherwise }\end{array}$ \\
\hline Region & $\begin{array}{l}6 \text { dummy variables for regions in Poland (NUTS } 1 \text { clas- } \\
\text { sification) and } 38 \text { dummy variables for Russia }\end{array}$ \\
\hline
\end{tabular}

Variables marked with * appear only in the Polish SD survey 
Table 8 Logit regressions for the probability of being unhappy, $P(k=1)$, Poland, 1991, 2000 and 2015. Source: own computation using the SD data

\begin{tabular}{|c|c|c|c|c|c|c|}
\hline & \multicolumn{2}{|l|}{1991} & \multicolumn{2}{|l|}{2000} & \multicolumn{2}{|l|}{2015} \\
\hline & Estimate & SE & Estimate & SE & Estimate & $\mathrm{SE}$ \\
\hline Female & 0.008 & $(0.088)$ & -0.087 & $(0.074)$ & 0.045 & $(0.076)$ \\
\hline Age 18-24 & $-1.007 * * *$ & $(0.202)$ & $-0.953 * * *$ & $(0.156)$ & $-0.989 * * *$ & $(0.173)$ \\
\hline Age $25-34$ & $-0.254 * *$ & $(0.114)$ & $-0.484 * * *$ & $(0.11)$ & $-0.516^{* * * *}$ & $(0.12)$ \\
\hline Age $45-54$ & $-0.362 * * *$ & $(0.123)$ & $0.296 * * *$ & $(0.097)$ & $0.279 * * *$ & $(0.103)$ \\
\hline Age 55-64 & -0.230 & $(0.145)$ & 0.180 & $(0.144)$ & $0.356^{* * *} *$ & $(0.104)$ \\
\hline Low education & $0.205 * *$ & $(0.097)$ & $0.209 * *$ & $(0.086)$ & 0.123 & $(0.082)$ \\
\hline High education & $-0.431 * *$ & $(0.191)$ & 0.074 & $(0.138)$ & -0.129 & $(0.114)$ \\
\hline Real income level & $-0.321 * * *$ & $(0.121)$ & $-0.486^{* * * *}$ & $(0.137)$ & $-0.218 * * *$ & $(0.066)$ \\
\hline Poor & -0.075 & $(0.214)$ & -0.029 & $(0.137)$ & $0.447 * * *$ & $(0.127)$ \\
\hline Rich & -0.178 & $(0.357)$ & -0.016 & $(0.249)$ & 0.133 & $(0.272)$ \\
\hline Relatively poor & 0.223 & $(0.224)$ & $0.505 * * *$ & $(0.144)$ & -0.030 & $(0.129)$ \\
\hline Relatively rich & 0.423 & $(0.358)$ & -0.078 & $(0.253)$ & $0.461 * *$ & $(0.229)$ \\
\hline Bad health & $0.717 * * *$ & $(0.109)$ & $0.609 * * *$ & $(0.092)$ & $1.065 * * *$ & $(0.092)$ \\
\hline Good health & $-0.480 * * *$ & $(0.096)$ & $-0.577 * * *$ & $(0.082)$ & $-0.900 * * *$ & $(0.083)$ \\
\hline Unemployed & $0.512 * * *$ & $(0.171)$ & $0.875 * * *$ & $(0.116)$ & $0.870 * * *$ & $(0.119)$ \\
\hline Retired & -0.081 & $(0.173)$ & -0.084 & $(0.166)$ & -0.126 & $(0.127)$ \\
\hline Inactive & -0.252 & $(0.16)$ & $0.205^{*}$ & $(0.118)$ & $0.230 * *$ & $(0.111)$ \\
\hline Disabled & -0.130 & $(0.146)$ & $0.244 * *$ & $(0.122)$ & -0.011 & $(0.127)$ \\
\hline Living in a large city & $-0.230 * *$ & $(0.108)$ & - & - & - & - \\
\hline Rural & -0.011 & $(0.104)$ & 0.023 & $(0.081)$ & $-0.210^{* * *}$ & $(0.075)$ \\
\hline Farmer & 0.092 & $(0.149)$ & 0.239 & $(0.152)$ & -0.045 & $(0.127)$ \\
\hline Married & $-0.962 * * *$ & $(0.206)$ & $-0.583 * * *$ & $(0.147)$ & $-0.678 * * *$ & $(0.131)$ \\
\hline No longer married & -0.088 & $(0.244)$ & $0.362 *$ & $(0.188)$ & $0.382 * * *$ & $(0.146)$ \\
\hline Having children & 0.059 & $(0.178)$ & -0.156 & $(0.124)$ & $-0.481 * * *$ & $(0.125)$ \\
\hline Number of friends & $-0.015^{* *}$ & $(0.007)$ & $-0.047 * * *$ & $(0.01)$ & $-0.038 * * *$ & $(0.009)$ \\
\hline Not taking part in religious services & $0.884 * * *$ & $(0.182)$ & $0.278 * * *$ & $(0.092)$ & $0.525 * * *$ & $(0.09)$ \\
\hline $\begin{array}{l}\text { Religious services less than } 4 \text { times/ } \\
\text { month }\end{array}$ & $0.167 *$ & $(0.093)$ & -0.013 & $(0.09)$ & $0.164 *$ & $(0.09)$ \\
\hline $\begin{array}{l}\text { Religious services more than } 4 \text { times/ } \\
\text { month }\end{array}$ & 0.033 & $(0.115)$ & $-0.215^{*}$ & $(0.113)$ & $0.241^{*}$ & $(0.132)$ \\
\hline Living in a big city & - & - & $-0.260 *$ & $(0.149)$ & $-0.277 * *$ & $(0.137)$ \\
\hline Having savings & - & - & $-0.514 * * *$ & $(0.092)$ & $-0.283 * * *$ & $(0.077)$ \\
\hline Doing community work & - & - & -0.082 & $(0.122)$ & -0.013 & $(0.098)$ \\
\hline Constant & $0.805 * * *$ & $(0.277)$ & $0.736^{* * *}$ & $(0.268)$ & $-0.366^{*}$ & $(0.221)$ \\
\hline$N$ & 3160 & & 5075 & & 14,709 & \\
\hline
\end{tabular}

$* * * p<0.01, * * p<0.05, * p<0.1$. Standard errors (SE) in parentheses. Regional dummies included, but not shown. Omitted categories are: 35-44 age group, medium level of education, fair health, employed, single (not married), taking part in religious services 4 times per month 


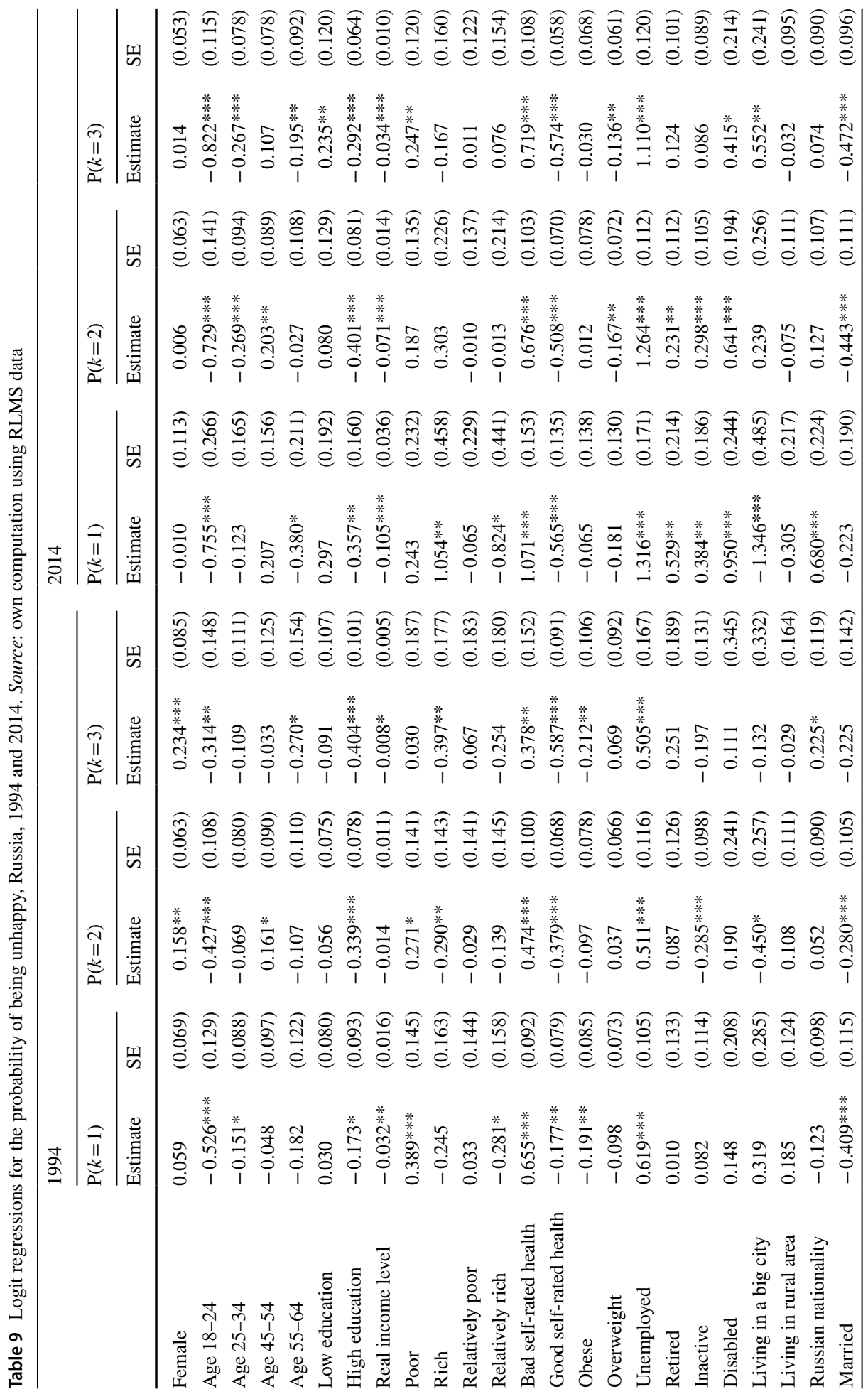




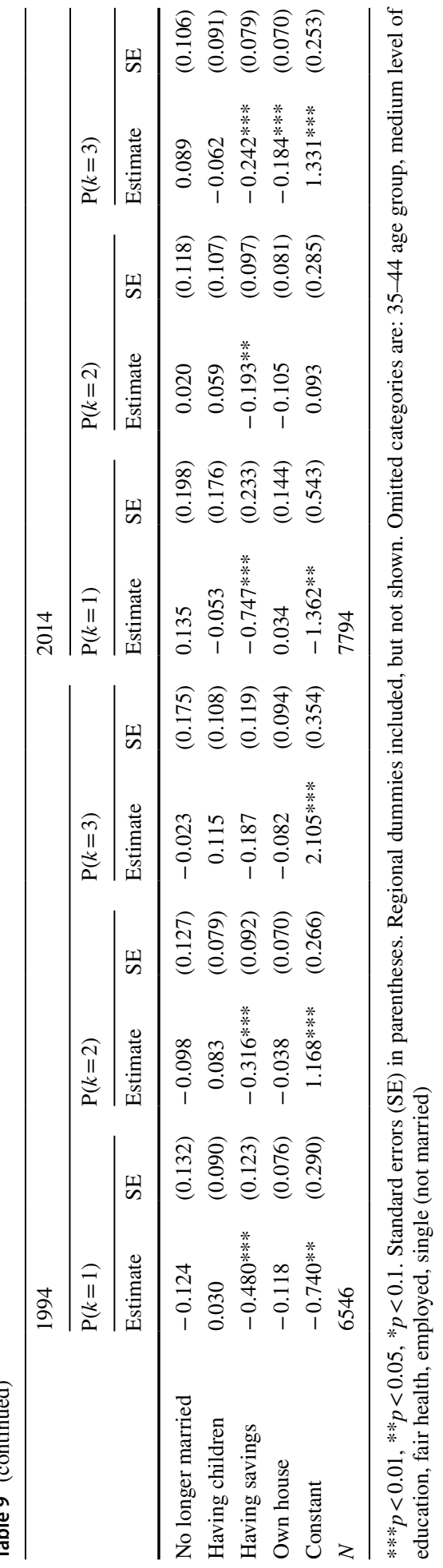




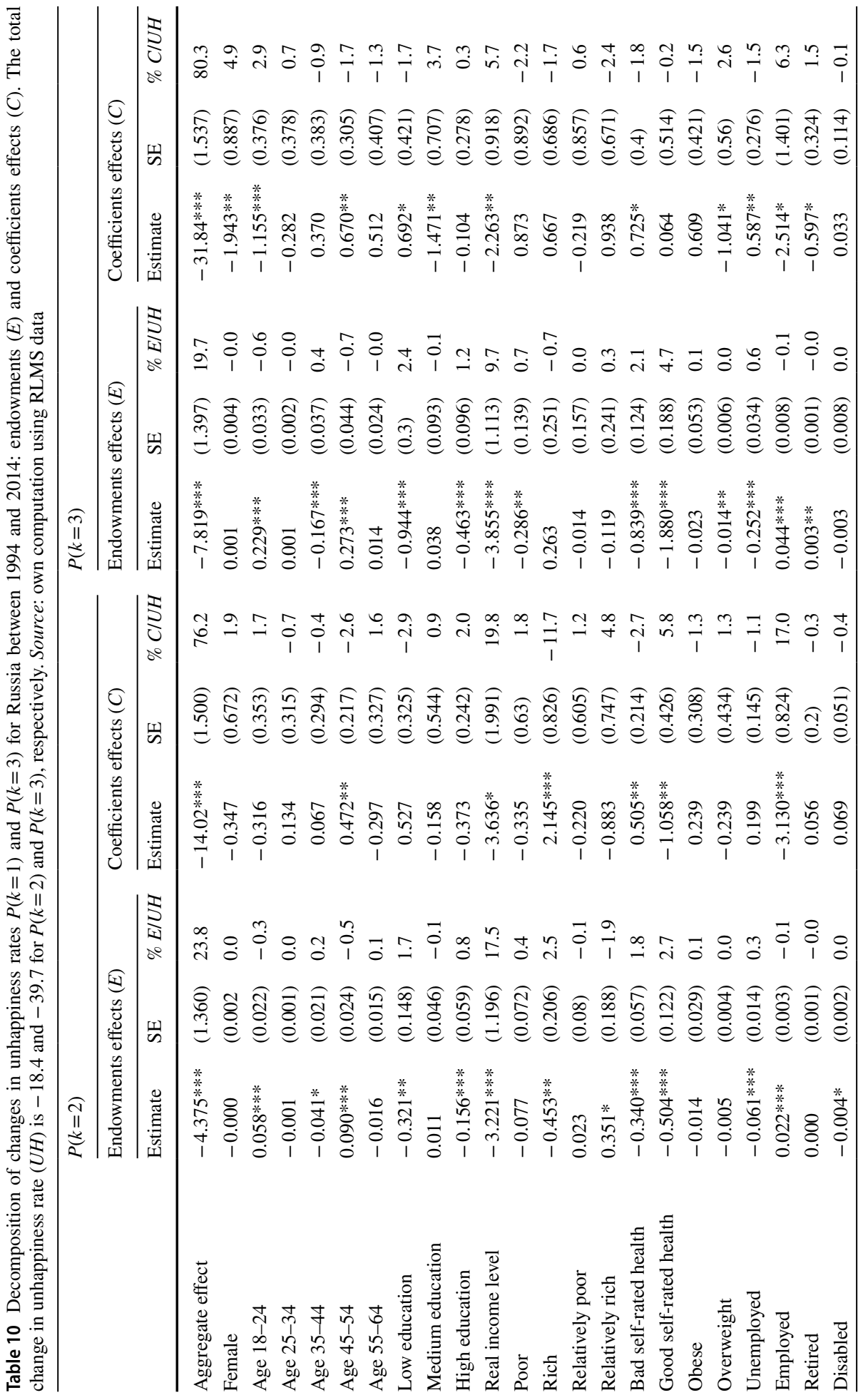




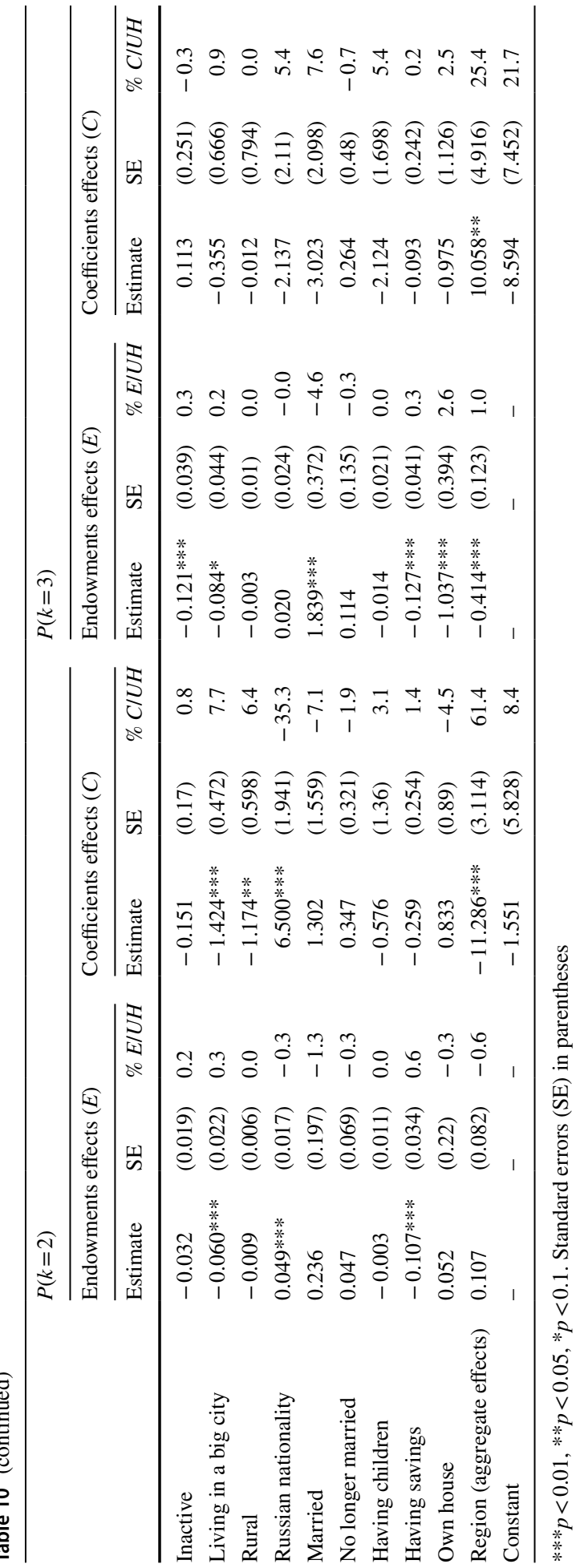




\section{References}

Alvaredo, F., \& Gasparini, L. (2015). Recent trends in inequality and poverty in developing countries. In A. B. Atkinson \& F. Bourguignon (Eds.), Handbook of income distribution, 2015 (Vol. 2, pp. 697-805). Amsterdam: Elsevier.

Angelescu, L. (2008). The effects of transition on life satisfaction in Poland. Working paper, Irvine, CA: Center for the Study of Democracy.

Angelini, V., Cavapozzi, D., Corazzini, L., \& Paccagnella, O. (2014). Do danes and italians rate life satisfaction in the same way? Using vignettes to correct for individual-specific scale biases. Oxford Bulletin of Economics and Statistics, 76(5), 643-666.

Baranowska, A., \& Matysiak, A. (2011). Does parenthood increase happiness? Evidence for Poland. Vienna Yearbook of Population Research, 9, 307-325.

Bartolini, S., Mikucka, M., \& Sarracino, F. (2015). Money, trust and happiness in transition countries: Evidence from time series. Social Indicators Research. https://doi.org/10.1007/s11205-015-1130-3

Becchetti, L., Massari, R., \& Naticchioni, P. (2014). The drivers of happiness inequality: Suggestions for promoting social cohesion. Oxford Economic Papers, 66(2), 419-442.

Beegle, K., Himelein, K., \& Ravallion, M. (2012). Frame-of-reference bias in subjective welfare. Journal of Economic Behavior \& Organization, 81(2), 556-570.

Bhaumik, S. K., \& Gang, I. N., \& Yun, M.-S. (2006). A note on decomposing differences in poverty incidence using regression estimates: Algorithm and example. IZA discussion papers (Vol. 2262). Institute for the Study of Labor (IZA).

Binder, M., \& Coad, A. (2011). From average Joe's happiness to miserable Jane and cheerful John: Using quantile regressions to analyze the full subjective well-being distribution. Journal of Economic Behavior \& Organization, 79(3), 275-290.

Bjørnskov, C., \& Ming-Chang, T. (2015). How do institutions affect happiness and misery? A tale of two tails. Comparative Sociology, 14(3), 353-385.

Blinder, A. S. (1973). Wage discrimination: Reduced Form and structural estimates. Journal of Human Resources, 8(4), 436-455.

Chrostek, P. (2016). An empirical investigation into the determinants and persistence of happiness and life evaluation. Journal of Happiness Studies, 17(1), 413-430.

Clark, A. E. (2016). SWB as a measure of individual well-being. In M. Adler \& M. Fleurbaey (Eds.), Oxford handbook of well-being and public policy (pp. 518-552). Oxford: Oxford University Press.

Clark, A. E., Flèche, S., \& Senik, C. (2014). The Great Happiness Moderation. In A. E. Clark \& C. Senik (Eds.), Happiness and economic growth: Lessons from developing countries (pp. 32-139). Oxford: Oxford University Press.

Clark, A. E., Fleche, S., \& Senik, C. (2015). Economic growth evens out happiness: Evidence from six surveys. Review of Income and Wealth. https://doi.org/10.1111/roiw.12190.

Clark, A. E., \& Senik, C. (2011). Is happiness different from flourishing? Cross-country evidence from the ESS. In Revue d'économie politique 2011/1 (Vol. 121, pp. 17-34).

Cojocaru, A. (2014). Fairness and inequality tolerance: Evidence from the Life in Transition survey. Journal of Comparative Economics, 42(3), 590-608.

Cojocaru, A., \& Diagne, M. F. (2015). How reliable and consistent are subjective measures of welfare in Europe and Central Asia? Economics of Transition, 23(1), 75-103.

Czapiński, J. (1998). The Poles' quality of living in times of social change. Institute of Social Studies: University of Warsaw.

Czapiński, J., \& Panek, T. (Eds.) (2015). Social diagnosis 2015. Objective and subjective quality of life in Poland. Available at https://www.diagnoza.com/data/report/report_2015.pdf. Accessed 21 Oct 2018.

Djankov, S., Nikolova, E., \& Zilinsky, J. (2016). The happiness gap in Eastern Europe. Journal of Comparative Economics., 44(1), 108-124.

Dolan, P., Peasgood, T., \& White, M. (2008). Do we really know what makes us happy? A review of the economic literature on the factors associated with subjective well-being. Journal of Economic Psychology, 29, 94-122.

Dutta, I., \& Foster, J. (2013). Inequality of happiness in the US: 1972-2010. Review of Income and Wealth, 59(3), 393-415.

Easterlin, R. A. (2009). Lost in transition: Life satisfaction on the road to capitalism. Journal of Economic Behavior \& Organization, 71(2), 130-145.

Ferreira, F., \& Ravallion, M. (2009). Poverty and inequality: The global context. In W. Salverda, B. Nolan, \& T. Smeeding (Eds.), The oxford handbook of economic inequality (pp. 599-636). Oxford: Oxford University Press. 
Ferrer-i-Carbonell, A., \& Frijters, P. (2004). How important is methodology for the estimates of the determinants of happiness? The Economic Journal, 114(497), 641-659.

Fortin, M. N., Lemieux, T., \& Firpo, S. (2011). Decomposition methods in economics. In O. Ashenfelter \& D. Card (Eds.), Handbook of labor economics (Vol. 4, pp. 1-102). Amsterdam: North Holland.

Frijters, P., Geishecker, I., Haisken-DeNew, J. P., \& Shields, M. A. (2006). Can the large swings in Russian life satisfaction be explained by ups and downs in real incomes? The Scandinavian Journal of Economics, 108(3), 433-458.

Gang, I. N., Sen, K., \& Yun, M.-S. (2006). Caste, ethnicity and poverty in rural India. Economic Development and Cultural Change, 54(2), 369-404.

Goff, L., Helliwell, J. F., \& Mayraz, G. (2016). The welfare costs of well-being inequality. NBER working paper no. 21900, National Bureau of Economic Research.

Gorodnichenko, Y., Peter, K. S., \& Stolyarov, D. (2010). Inequality and volatility moderation in Russia: Evidence from micro-level panel data on consumption and income. Review of Economic Dynamics, 13(1), 209-237.

Gradín, C. (2009). Why is poverty so high among Afro-Brazilians? A decomposition analysis of the racial poverty gap. The Journal of Development Studies, 45(9), 1426-1452.

Gradín, C. (2012). Poverty among minorities in the United States: Explaining the racial poverty gap for Blacks and Latinos. Applied Economics, 44(29), 3793-3804.

Graham, C., Eggers, A., \& Sukhtankar, S. (2004). Does happiness pay? An exploration based on panel data from Russia. Journal of Economic Behavior \& Organization, 55, 319-342.

Graham, C., \& Felton, A. (2005). Variance in obesity across countries and cohorts: A norms-based explanation using happiness surveys. CSED working paper series no. 42. Washington: Brookings Institution.

Grosfeld, I., \& Senik, C. (2010). The emerging aversion to inequality: Evidence from Poland 1992-2005. Economics of Transition, 18, 1-6.

Guriev, S., \& Zhuravskaya, E. (2009). (Un)happiness in transition. Journal of Economic Perspectives, 23(2), $143-168$.

Hayo, B. (2007). Happiness in transition: An empirical study on Eastern Europe. Economic Systems, 31(2), 204-221.

Hayo, B., \& Seifert, W. (2003). Subjective economic well-being in Eastern Europe. Journal of Economic Psychology, 24(3), 329-348.

Helliwell, J., Layard, R., \& Sachs, J. (2016). World happiness report 2016, update (Vol. I). New York: Sustainable Development Solutions Network.

Kakwani, N. (1993). Statistical inference in the measurement of poverty. The Review of Economics and Statistics, 75(4), 632-639.

Keane, M. P., \& Prasad, E. S. (2002). Inequality, transfers, and growth: New evidence from the economic transition in Poland. Review of Economics and Statistics, 84(2), 324-341.

Kingdon, G. G., \& Knight, J. (2006). Subjective well-being poverty vs. income poverty and capabilities poverty? The Journal of Development Studies, 42(7), 1199-1224.

Kolosnitsyna, M., Khorkina, N., \& Dorzhiev, K. (2014), What happens to happiness when people get older? Socio-economic determinants of life satisfaction in later life higher school of economics research paper no. WP BRP 68/EC/2014.

Kozyreva, P., Kosolapov, M., \& Popkin, B. M. (2016). Data resource profile: The Russia Longitudinal Monitoring Survey-Higher School of Economics (RLMS-HSE) Phase II: Monitoring the economic and health situation in Russia, 1994-2013. International Journal of Epidemiology, 45(2), 395-401.

Kozyreva, P., \& Sabirianova Peter, K. (2015). Economic change in Russia: Twenty years of the Russian Longitudinal Monitoring Survey. Economics of Transition, 23(2), 293-298.

Lelkes, O. (2013). Minimising misery: A new strategy for public policies instead of maximising happiness? Social Indicators Research, 114(1), 121-137.

Litchfield, J., Reilly, B., \& Veneziani, M. (2012). An analysis of life satisfaction in Albania: An heteroscedastic ordered probit model approach. Journal of Economic Behavior \& Organization, 81(3), 731-741.

MacKerron, G. (2012). Happiness economics from 35000 feet. Journal of Economic Surveys, 26(4), $705-735$.

Michoń, P. (2014). Re-marry fast, die young, the gender related happiness inequalities among polish adults. In E. Eckerman (Ed.), Gender, lifespan and quality of life, social indicators research series (Vol. 53, pp. 157-172). New York: Springer.

Mikucka, M. (2015). How does parenthood affect life satisfaction in Russia? MPRA paper no. 65376. University Library of Munich, Germany.

Milanovic, B. (1999). Explaining the increase in inequality during the transition. Economics of Transition, $7(2), 299-341$. 
Niimi, Y. (2015). Can happiness provide new insights into social inequality? Evidence from Japan, AGI working paper series 2015-12. Asian Growth Research Institute.

Nikolova, E., \& Sanfey, P. (2016). How much should we trust life satisfaction data? Evidence from the life in transition survey. Journal of Comparative Economics, 44(3), 720-731.

Oaxaca, R. L. (1973). Male-female wage differentials in urban labor markets. International Economic Review, 14(3), 693-709.

Okulicz-Kozaryn, A. (2015). Freedom and life satisfaction in transition. Society and Economy in Central and Eastern Europe, 37(2), 143-164.

Ott, J. (2013). Greater happiness for a greater number: Some non-controversial options for governments. The Exploration of Happiness (pp. 321-340). Netherlands: Springer.

Ovaska, T., \& Takashima, R. (2010). Does a rising tide lift all the boats? Explaining the national inequality of happiness, Journal of Economic Issues, 44, 205-224.

Popova, O. (2014). Can religion insure against aggregate shocks to happiness? The case of transition countries. Journal of Comparative Economics, 42(3), 804-818.

Powers, D. A. (2016). Erosion of advantage: Decomposing differences in infant mortality rates among older non-hispanic white and mexican-origin mothers. Population Research and Policy Review, 35(1), 23-48.

Powers, D. A., Yoshioka, H., \& Yun, M. S. (2011). mvdemp: Multivariate decomposition for nonlinear response models. Stata Journal, 11(4), 556-576.

Sanfey, P., \& Teksoz, U. (2007). Does transition make you happy? Economics of Transition, 15(4), 707-731.

Selezneva, E. (2011). Surveying transitional experience and subjective well-being: Income, work, family. Economic Systems, 35(2), 139-157.

Selezneva, E. (2016). Happiness in transition. In J. Hölscher \& H. Tomann (Eds.), Palgrave dictionary of emerging markets and transition economics (pp. 545-564). Basingstoke: Palgrave Macmillan.

Senik, C. (2004). When information dominates comparison: Learning from Russian subjective panel data. Journal of Public Economics, 88(9), 2099-2123.

Senik, C. (2008). Ambition and jealousy: Income interactions in the "Old" Europe versus the "New" Europe and the United States. Economica, 75(299), 495-513.

Stevenson, B., \& Wolfers, J. (2008). Happiness inequality in the United States. Journal of Legal Studies, 37, 33-79.

Szelewa, D. (2017). From Implicit to explicit familialism: Post-1989 family policy reforms in Poland. In D. Auth, J. Hergenhan, \& B. Holland-Cunz (Eds.), Gender and family in European economic policy. Developments in the New Millennium (pp. 129-152). Basingstoke: Palgrave Macmillan.

Taber, D. R., Robinson, W. R., Bleich, S. N., \& Wang, Y. C. (2016). Deconstructing race and gender differences in adolescent obesity: Oaxaca-blinder decomposition. Obesity, 24(3), 719-726.

Van Praag, B. M. S. (2011). Well-being inequality and reference groups: An agenda for new research. Journal of Economic Inequality, 9, 111-127.

Veenhoven, R. (1990). Inequality in happiness, inequality in countries compared between countries. Paper presented at the 12 th work congress of sociology, Madrid.

Veenhoven, R. (2005a). Inequality of happiness in nations. Journal of Happiness Studies, 6, 351-355.

Veenhoven, R. (2005b). Return of inequality in modern society? Test by dispersion of life satisfaction across time and nations. Journal of Happiness Studies, 6, 457-487.

Wang, X., Shang, X., \& Xu, L. (2011). Subjective well-being poverty of the elderly population in China. Social Policy \& Administration, 45(6), 714-731.

Weimann, J., Knabe, A., \& Schöb, R. (2015). Measuring happiness: The economics of wellbeing. Cambridge, MA: MIT Press.

Yang, J., Liu, K., \& Zhang, Y. (2015). Happiness inequality in China. MPRA paper 66623, University Library of Munich, Germany.

Yun, M.-S. (2004). Decomposing differences in the first moment. Economics Letters, 82(2), 275-280.

Yun, M.-S. (2005). A simple solution to the identification problem in detailed wage decompositions. Economic Inquiry, 43(4), 766-772.

Yun, M. S. (2008). Identification problem and detailed Oaxaca decomposition: a general solution and inference. Journal of economic and social measurement, 33(1), 27-38.

Zagórski, K. (2011). Income and happiness in time of post-communist modernization. Social Indicators Research, 104(2), 331-349.

Zhang, H., d'Uva, T. B., \& van Doorslaer, E. (2015). The gender health gap in China: A decomposition analysis. Economics \& Human Biology, 18, 13-26. 